\title{
Service Robots and Humanitarian Demining
}

\author{
Maki K. Habib \\ Graduate School of Science and Engineering, Saga University \\ Japan
}

\section{Introduction}

Landmines are prominent weapon and they are so effective, yet so cheap, and easy to make and lay. A landmine is a type of self-contained explosive device, which is placed onto or into the ground to constitute a minefield, and it is designed to destroy or damage equipment or personnel. A mine is detonated by the action of its target (a vehicle, a person, an animal, etc.), the passage of time, or controlled means. A minefield is an area of ground containing mines laid with or without a pattern. They are the most effective means of reinforcing the terrain to stop, slow, or force the enemy to pass into areas where he can be killed. There are two types of land-based mines: anti-tank (AT) and anti-personnel (AP). The production costs of AP mines are roughly between 3 and 30 US\$. AP mines can kill or incapacitate their victims. The removal and destruction of all forms of dangerous battlefield debris, particularly landmines and other unexploded ordnance (UXO), are vital prerequisites for any region to recover from the aftermath of a war. Additional major effect of mines is to deny access to land and its resources, causing deprivation and social problems among the affected populations. Besides this, the medical, social, economic, and environmental consequences are immense (O'Malley, 1993; Blagden, 1993; Physicians for Human Rights, ธิ 1993; US Department of State, 1994; King, 1997; ICRC, 1998). The international Committee of $\underset{0}{0}$ the Red Cross (ICRC) estimates that the casualty rate from mines currently exceeds 26,000 $\stackrel{\equiv}{=}$ persons every year. It is estimated that 800 persons are killed and 1,200 maimed each month 응 by landmines around the world (ICRC, 1996a; ICRC, 1996b; ICRC, 1998). The primary 을 victims are unarmed civilians and among them children are particularly affected. Worldwide there are some 300,000-400,000 landmine survivors. Survivors face terrible physical, psychological and socio-economic difficulties. The direct cost of medical treatment and rehabilitation exceeds US\$750 million. This figure is very small compared to the o projected cost of clearing the existing mines. The current cost rate of clearing one mine is ON ranging between 300-1000 US\$ per mine (depending on the mine infected area and the $\stackrel{0}{\pi}$ number of false alarms). United Nation Department of Human Affairs (UNDHA) assesses *ै that there are more than 100 million mines that are scattered across the world and pose significant hazards in more than 68 countries that need to be cleared (O'Malley, 1993; \& Blagden, 1993; Physicians for Human Rights, 1993; US Department of State, 1994; King, 1997; \& Habib, 2002b). Currently, there are 2 to 5 millions of new mines continuing to be laid every year. Additional stockpiles exceeding 100 million mines are held in over 100 nations, and 50 $\Phi$ of these nations still producing a further 5 million new mines every year. The rate of clearance is far slower. There exists about 2000 types of mines around the world; among 
these, there are more than 650 types of AP mines. What happens when a landmine explodes is also variable. A number of sources, such as pressure, movement, sound, magnetism, and vibration can trigger a landmine. AP mines commonly use the pressure of a person's foot as a triggering means, but tripwires are also frequently employed. Most AP mines can be classified into one of the following four categories: blast, fragmentation, directional, and bounding devices. These mines range from very simple devices to high technology (O'Malley, 1993; US Department of State, 1994). Some types of modern mines are designed to self-destruct, or chemically render themselves inert after a period of weeks or months to reduce the likelihood of civilian casualties at the conflict's end. Conventional landmines around the world do not have self-destructive mechanisms and they stay active for long time. Modern landmines are fabricated from sophisticated non-metallic materials. New, smaller, lightweight, more lethal mines are now providing the capability for rapid emplacement of self-destructing AT and AP minefields by a variety of delivery modes. These modes range from manual emplacement to launchers on vehicles and both rotary and fixed-wing aircraft. Even more radical changes are coming in mines that are capable of sensing the direction and type of threat. These mines will also be able to be turned on and off, employing their own electronic countermeasures to ensure survivability against enemy countermine operations. Although demining has been given top priority, currently mine's clearing operation is a labor-intensive, slow, very dangerous, expensive, and low technology operation. Landmines are usually simple devices, readily manufactured anywhere, easy to lay and yet so difficult and dangerous to find and destroy. They are harmful because of their unknown positions and often difficult to detect. The fundamental goals of humanitarian landmine clearance is to detect and clear mines from infected areas efficiently, reliably and as safely and as rapidly as possible while keeping cost to the minimum, in order to make these areas economically viable and usable for the development without fear.

Applying technology to humanitarian demining is a stimulating objective. Detecting and removing AP mines seems to be a perfect application for robots. However, this need to have a good understanding of the problem and a careful analysis must filter the goals in order to avoid deception and increase the possibility of achieving results (Nicoud, 1996). Mechanized and robotized solutions properly sized with suitable modularized mechanized structure and well adapted to local conditions of minefields can greatly improve the safety of personnel as well as work efficiency and flexibility. Such intelligent and flexible machines can speed the clearance process when used in combination with handheld mine detection tools. They may also be useful in quickly verifying that an area is clear of landmines so that manual cleaners can concentrate on those areas that are most likely to be infested. In addition, solving this problem presents great challenges in robotic mechanics and mobility, sensors, sensor integration and sensor fusion, autonomous or semi autonomous navigation, and machine intelligence. Furthermore, the use of many robots working and coordinating their movement will improve the productivity of the overall mine detection process with team cooperation and coordination. A good deal of research and development has gone into mechanical mine clearance (mostly military equipment), in order to destroy mines quickly, and to avoid the necessity of deminers making physical contact with the mines at all. Almost no equipment has been developed specifically to fulfill humanitarian mine clearance objectives and for this, there is no form of any available mechanical mine clearance technologies that can give the high clearance ratio to help achieving humanitarian mine clearance standards effectively while minimizing the environmental impact. Greater resources need to be devoted to demining both to immediate clearance and to the development of innovated detection and clearance 
equipment and technologies. This chapter introduces the problem of mines and its impact. It also, focuses on the aspects of demining, the requirements and the difficulties facing it. Then, the chapter evaluates the available mine clearance technologies along with their limitations and discusses the development efforts to automate tasks related to demining process wherever possible through mechanization and robotization. It aims to evaluate current humanitarian demining situations and technologies for the purpose to improve existing technologies and develop an innovative one. In addition, it introduces solutions and priorities beside the requirements in terms of technical features and design capabilities of a mobile platform that can accelerate the demining process, preserve the life of the mine clearing personnel and enhance safety, and achieve cost effective measures.

\section{Service Robots}

Between the 60 s and end of 80 s, most robot applications were related to industries and manufacturing and these robots were called industrial robots that were mainly intended for rationalizing production at a manufacturing site. A robot is usually an extremely flexible and complex machine, which integrates science and engineering. Each technology used in the robotic system has its own challenges to offer. The opportunity for robotics to help humanity arises when there are not enough skilled people available to do certain tasks at a reasonable price, like elder care. Much thought has been put into development of robotic helpers for the infirmed and elderly. Advances in micro-technology, microprocessors, sensor technology, smart materials, signal processing and computing technologies, information and communication technologies, navigation technology, and biological inspiration in learning and decision-making capabilities have led to breakthrough in the invention of a new generation of robots called service robots. Service robot is a generic term covering all robots that are not intended for industrial use, i.e., perform services useful to the well being of humans, and other equipment (maintenance, repair, cleaning etc.), and are not intended for rationalizing production. The development and operation of service robots provide invaluable experience as they form an intermediate stage in the evolution from the industrial robot to the personal robot, which is recognized as an important application area for the near future. The new types of robots aim to achieve high level of intelligence, functionality, flexibility, adaptability, mobility, intractability, and efficiency to perform wide range of work in complex and hazardous environment, and to provide and perform services of various kinds to human users and society. Crucial prerequisites for performing services are safety, mobility, and autonomy supported by strong sensory perception. Such robots should be good at what they can do, and have the ability to work at a larger degree of unstructured environments. In addition, humanrobot interaction plays a crucial role in the evolving market for intelligent personal robots. Service robots are manipulative and dexterous, and have the capability to interact, perform tasks autonomously/semi autonomously (multi modes operation), and they are portable.

Three classes of service robots can be distinguished, the first being robots to replace humans at work in dirty, hazardous and tedious operations, such as working under high temperature, in a radioactive environment, in a vacuum, underwater, fire fighting, space, demining, military, construction, cleaning etc. The second class includes robots that operate with human beings to alleviate incommodity or to increase comfort, such as, entertainment, rehabilitation, assist the elderly and severely disabled, housekeeping, etc. The third class includes robots that operate on human being, such as medical robots mainly for surgery, treatment and diagnosis.

Service robots with their free navigation capability target a wide range of applications, such 
as agriculture \& harvesting, healthcare/rehabilitation, cleaning (house, public, industry), construction, humanitarian demining, entertainment, fire fighting, hobby/leisure, hotel/restaurant, marketing, food industry, medical, mining, surveillance, inspection and maintenance, search \& rescue, guides \& office, nuclear power, transport, refilling \& refueling, hazardous environments, military, sporting, space, underwater, etc. Such robots aim to offer a useful service with reasonable cost compared to expected duties.

\section{Humanitarian demining}

Humanitarian demining scenarios differ from military ones in many respects. The objectives and philosophy are different. Solutions developed for the military are generally not suitable for humanitarian demining. Humanitarian demining is a critical first step for reconstruction of post-conflict countries and its goal is the total clearance of the land from all types of mines and UXOs. It requires that all mines in populated areas and other infrastructures are located, uncovered and removed or destroyed. It is carried out in a postconflict context, and its objective to decontaminate mine-infected areas and to make sure that there is not a mine being left in the ground. The important outcome of humanitarian demining is to make land safer for daily living and restoration to what it was prior to the hostilities. Also, it is allowing people to use their land without fear; allowing refugees to return home, schools to be reopened, land to be used for farming and critical infrastructure to be rebuilt (ESPIRIT HPCN, 1997; Bruschini et al., 1999; Habib, 2002b; Goose, 2004). The standard to which clearance must be achieved is extremely high as there is a need to have at least 99.6\% (the standard required by UNDHA) successful detection and removal rate (Blagden, 1993), and a $100 \%$ to a certain depth according to International Mine Action Standards (IMAS).

The amount of time it takes to clear an area is less important than the safety of the clearance personnel and the reliability and accuracy of the demining process. Safety is of utmost importance, and casualties are unacceptable. Any system to be developed should compliment this effort, not to hamper it or simply move the problem elsewhere. The risks to those carrying out the task must also be maintained at a lower level than might be acceptable in a military situation. Another consideration by humanitarian demining is the use of land for development, i.e., there is a need to reduce the environmental impact that may results from the demining operation. The currently available technologies are not suited to achieve these objectives of humanitarian demining. Until now, detection and clearance in humanitarian demining very often relies on manual methods as primary procedure. The problem resides primarily in the detection phase first, and then how to increase productivity by speeding up demining process reliably and safely. Technology has become the solution to many long-standing problems, and while current technology may be effective, it is far too limited to address fully the huge, complex and difficult landmine problem facing the world.

\section{Humanitarian Mine Clearance and Difficulties}

Humanitarian demining requires that the entire land area to be free of mines and hence the need to detect, locates, and removes reliably every single mine, and UXO from a targeted ground. The development of new demining technologies is difficult because of the tremendous diversity of terrains and environmental conditions in which mines are laid and because of the wide variety of landmines. There is wide range of terrains (rocky, rolling, 
flat, desert, beaches, hillside, muddy, river, canal bank, forest, trench, etc.) whereas mines are often laid. The environmental conditions may cover weather (hot, humid, rainy, cold, windy), the density of vegetation (heavy, medium, small, none), and type of soil (soft, sand, cultivated, hard clay, covered by snow, covered with water). In addition, residential, industrial and agriculture area, each has its own features and needs to be considered. Landmines are many in terms of type and size. The size ranges from small enough to fit into a hand of a child, and weighting as little as 50 grams, to large antitank mines. AP mines come in all shapes and colors are made from a variety of materials, metallic and nonmetallic. Metal detector works well with metal cased mines, but metal in modern mines has been increasingly replaced by plastic and wood. New mines will soon be undetectable by their metallic content. AP mines can be laid anywhere and can be set off in a number of ways because the activation mechanisms available for these mines are not the same. Activation methods can be classified into three categories, pressure, electronic, and command detonation (remote control). Mines may have been in place for many years, they might be corroded, waterlogged, impregnated with mud or dirt, and can behave quite unpredictable. Some mines were buried too deep to stop more organized forces finding them with metal detectors. Deeper mines may not detonate when the ground is hard, but later rain may soften the ground to the point where even a child's footstep will set them off. Trip-wires may be caught up in overgrown bushes, grass or roots. In addition, there is no accurate estimate on the size of the contaminated land and the number of mines laid in it. The diversity of the mine threat points out to the need for different types of sensors and equipment to detect and neutralize landmines. The requirements to develop equipment for use by deminers with different training levels, cultures, and education levels greatly add to the challenge. The solution to this problem is very difficult and challenging one from a scientific and technical point of view because, given the nature of landmines and the requirements of humanitarian demining, any instrument must be $100 \%$ reliable for the safety of the operators and the people whom will use the land (Blagden, 1993; Habib 2002b). Developing new technologies is critical to the success of the efforts intended to reduce this threat.

\section{Humanitarian Mine Clearance Process and Needs}

Land mine clearance process can be divided into the following essential five phases (Habib, 2002b).

\subsection{Locating and identifying minefields for the purpose to map them}

Demining is very costly and searching unmined area is adding extra high cost. Therefore, it is important first to identify and mark what areas are mined using different approaches through survey and remote sensing along with other techniques. A clearance priority rating should be given to each suspected mined area to reflect the urgency for clearance while considering social and economical factors.

\subsection{Preparing the minefield for the clearance operation}

The normal obstacles facing deminers that considerably slow down the operation are surface vegetation and subsurface metal contamination. Currently, as much as $70 \%$ of deminer's time spent in checking for tripwires and cutting back vegetation through the demining process. 


\subsection{Locating and Marking Individual Mines}

Different ways are used to detect individual mines such as manual probing, dogs, metal detectors, thermal imaging, electromagnetic technologies, nuclear technologies, chemical techniques, biosensors, etc. Generally, such methods are limited by soil conditions, vegetation, mine size and composition, soil minerals, burial depth, and grazing angle. Some of these technologies are still under development and experimentation. Cost and size is among the difficulties in deploying advanced and high-tech sensors.

\subsection{Removing the threat of the detected mines}

Once a mine has been located and marked, it must be neutralized to render its harmless. Detection and neutralization of landmines are difficult tasks, as there are a lot of different types of mines. These differences can be situated on different levels, the geometry of the mines with the materials used for the casing, or the fusing of the mine ranging from simple pressure fuses to more sophisticated ones as magnetic, acoustic, seismic, etc. The most difficult mines to detect are the pressure mines. Among the available demining methods, there exist different means of mine neutralization.

\subsection{Quality Control Measures.}

There is a need to verify that the required demining standards have been achieved, i.e., to assure with high level of confidence that the cleared area is free from mines and UXOs.

The weather and environmental conditions along with ground surface movement should be considered as factors to schedule demining activities, due to its impact on deminer's and equipment reliable performance.

\section{Solutions and Priorities}

Current demining technology is slow, expensive, and dangerous. The current rate of humanitarian mine clearing is about 100 thousand per year. It is estimated that the current demining rate is about 10-20 times slower than the laying rate, i.e., for every mine cleared 10-20 mines are laid. Therefore, to stabilize the mine situation, it is necessary to increase the current capability of mine clearance by 10-20 times. Hence, it becomes urgent to develop detection (individual mine, and area mine detection), identification and removal technologies and techniques to increase the efficiency of demining operations by several orders of magnitude to achieve a substantial reduction to the threat of $\mathrm{AP}$ mines within a reasonable timeframe and at an affordable cost.

The priorities for research and development in the field of humanitarian demining require strategies that should start with the following needs:

a) To develop reliable and accurate techniques that can enhance the performance of the demining process and allow efficient area detection of minefields. There is an urgent need to recognize and reliably locate minefields and isolate them by defining proper signs and limits to make the public aware, and to avoid further accidents.

b) To have quality-training programs that fit the needs of local environment. Such training programs need to integrate cultural, environmental and operational considerations when developed.

c) To enhance the safety of deminers by providing them with suitable protective clothing and equipment and by isolating them from direct physical contact with the mines and UXOs as possible. 
d) To enhance the performance of the sensors and the deminers. To achieve this, there is a need to develop efficient techniques for sensor integration (array of homogeneous or heterogeneous sensors) with advance level of data fusion and signal processing algorithms that can confirm the detection and lead to the identification of mine parameters needed for the next actions.

e) To develop a portable, reliable and easy to use handheld approach to sensor movement that is still required in difficult and physically constraint environments (woods, uneven terrain, residential, etc.) although such approach is slow and hazardous for the individuals. Therefore, the sensors can be integrated with vehicle-based platforms to support automatic mine clearance in open areas.

f) To use information and communication technologies aiming to enhance contact, experience exchange, research, planning and to share results and data among all parties and personnel within the demining community.

g) To mechanize vegetation cutting. However, it would be better to find a technology that can detect and mark mines without having to cut vegetation.

h) To increase mine clearance daily performance by improving productivity, accuracy, and increase safety of demining personnel. There is a need to have an automatic means of moving the portable mine detection device as it searches for landmines. Hence, it is important to automate/mechanize the detection and removal processes of mines, and to improve the safety of the deminers through the use of efficient, reliable and cost effective humanitarian mine action equipment (such as robots, flexible mechanisms, etc.), that have minimum environmental impact. It is necessary to have a robot with efficient surface locomotion concept and mobility that is well adapted to unstructured environment. The design should integrate proper balance between maneuverability, stability, speed, and the ability to overcome obstacles. Such robots, should have decision-making capability to locate, mark or neutralize individual mines precisely.

i) To have efficient quality control assurance methods that is reliable and accurate in ensuring that an area is clear of mines.

In order to approach proper and practical solutions for the problem, there is a need for the scientists in each discipline and deminers to share their knowledge and the results of their experience and experiments in order to design and test viable solutions for humanitarian demining.

The challenges associated with configuring humanitarian demining equipments are many. Technologies to be developed should take into account the facts that many of the demining operators will have had minimal formal education and that the countries where the equipment is to be used have poor technological infrastructure for equipment maintenance, operation, and deployment. The resultant system must be inexpensive and easy to use with minimal training by locals. In addition, the equipment must be flexible and modular to address a variety of clearance tasks and for case-by-case scenarios. Furthermore, the logistical support of the equipment must be consistent with third world countries.

\section{Mine Detection and Sensing Technologies}

Mine detection represents the slowest and the most important step within the demining process, and the quality of mine detector affects the efficiency and safety of this process. Mine detection targets are to achieve a high probability of detection rate while maintaining 
low probability of false alarm. The probability of false alarm rate is directly proportional to the time and cost of demining by a large factor. Hence, it is important to develop more effective detection technology that speed up the detection process, maximize detection reliability and accuracy, reduce false alarm rate, improve the ability to positively discriminate landmines from other buried objects and metallic debris, and enhance safety and protection for deminers. In addition, there is a need to have simple, flexible and friendly user interaction that allows safe operation without the need for extensive training. Such approach needs to incorporate the strength of sensing technologies with efficient mathematical, theoretic approaches, and techniques for analyzing complex incoming signals from mine detectors to improve mine detectability. This leads to maximize the performance of the equipment through the optimization of signal processing and operational procedures. Furthermore, careful study of the limitations of any tool with regard to the location, environment, and soil composition is critically important beside preparing the required operational and maintenance skills. Keeping in mind that not all high-tech solutions may be workable in different soil and environmental conditions. The detection technologies are presently in varying stages of development. Each has its own strength and weaknesses. The development phase of such new technologies requires a well-established set of testing facilities at the laboratory level that carried out in conditions closely follow those of the mine affected area, and at the real site. This should be followed by having extensive field trails in real scenarios to validate the new technologies under actual field conditions for the purpose to specify benefits and limitations of different methods. The work must be performed in close cooperation with end-users of the equipment and real deminers should carry out the test at a real site, in order to ensure that the developments are consistent with the practical operational procedures in the context of humanitarian demining, and that it is fulfilling user requirements. In addition, there is a need to have reliable process of global standard for assessing the availability, suitability, and affordability of technology with enabling technology represented by common information tools that enable these assessments and evaluations. The benchmarking is going to enhance the performance levels that enable the development of reliable and accurate equipment, systems and algorithms.

Methods of detecting mines vary from, simple in technology but exhaustive searching by humans using some combination of metal detectors and manual probing, to a variety of high biological and electronic technologies. The effectiveness of metal detectors can be inhibited by mines with extremely low metal content or by soils with high ferrous content and hence other detection techniques have been and are being investigated. Another technique that is widely used is the direct detection of explosive material by smell using a dog (Sieber, 1995). Trained dogs are the best known explosive detectors but they need excessive training and inherently unreliable because they are greatly impeded by windy conditions, and have only $50-60 \%$ accuracy.

New technologies are being investigated to improve the reliability and speedup the detection operation, some of these technologies are: Electromagnetic Induction metal detectors (EMI), Infrared Imaging, Ground Penetrating Radar (GPR), Acoustics, Acoustic Imaging, Thermal Neutron Activation (TNA), Photoacoustic Spectroscopy, Nuclear Quadrupole Resonance (NQR), X-ray tomography, Neutron back-scattering, Biosensors, Commercial sniffers, etc. (Healy \& Webber, 1993; Van Westen, 1993; Hewish \& Ness, 1995; Sieber, 1995; McFee, 1996; Cain \& Meidinger, 1996; Habib, 2001a).

Currently, there is no single sensor technology that has the capability to attain good levels of detection for the available AP mines while having a low false alarm rate under various types of soil, different weather, all types of mines, and facing many types of false targets. If one 
sensor can detect a mine with a certain success rate coupled with a certain probability of generating a false alarm, could two sensors working together do a better job? The idea of developing multi sensor solutions involving two or more sensors coupled to computer based decision support systems with advanced signal processing techniques is attractive and is advocated by many as a fruitful line of development. Hence, there is a need to use complementary sensor technologies and to do an appropriate sensor data fusion. The ultimate purpose is to have a system that improves detection, validation and recognition of buried items for the purpose to reduce false alarm rates and to overcome current landmine detection limitations. A promising solution will be to apply fusion of sensory information on various sensor outputs through the use of advanced signal processing techniques, by integrating different sensor technologies reacting to different physical characteristics of buried objects. Here two main steps can be distinguished: first the presence of an object must be detected, and secondly this object has to be identified as being a mine or other. Critical to demining is the ability to distinguish fragments or stones from the target material in real time. Studying the characteristics of the data stream of each sensor separately is essential in order to extract those properties that allow discrimination between these two categories. There is a need to develop or enhance the currently available sensors and to use complementary sensor technologies and have appropriate sensor data fusion techniques. Sensor fusion using soft computing methods such as fuzzy logic, neural networks and rough set theory must be further explored and computationally inexpensive methods of combining sensory data must be designed. These methods should also have the capability to assess the quality of the mined area once the mines have been cleared.

\section{Humanitarian Demining Techniques}

The initial responses to the mine problem were essentially military in their structure and philosophy. The currently used demining methods are not safe for both, those clearing the mines, and those who must thereafter occupy the land that has been cleared. The methods are neither cost effective nor efficient.

Mine clearance itself can be accomplished through different methods with varying levels of technology, but the most laborious way is still the most reliable. Currently, almost all humanitarian mine clearance is still performed by hand clearance method that uses 'prodding' or 'probing'. Prodder consists of $30 \mathrm{~cm}$ long prod that deminer inserts into the soil at a shallow angle (approximately 30 degrees). It is the procedure where mines are manually detected and destroyed/neutralized by a human deminer. Manual probing is slow, labor intensive and extremely dangerous and stressful process.

Mechanical approaches rely on the use of motorized mine-clearers in which their design is influenced by the military demining requirements. Machines destroy or activate mines mechanically by hitting or milling the ground. A number of mechanical mine clearing machines have been constructed or adapted from military vehicles, armored vehicles, or commercially available agriculture vehicles of the same or similar type, with same or reduced size (Habib, 2001b). Mechanical mine clearance systems aim to unearth mines or force them to explode under the pressure of heavy machinery and associated tools. Mechanical clearance can cover more ground in less time than manual deminers and mine detection dogs. They are mostly appropriate in large and wide areas without dense vegetation or steep grades. In small paths or thick bush, such machines simply cannot maneuver. Thus, mechanical mine clearance is particularly suited for roads, and favorable 
terrain such as flat, and sandy areas. Large mechanical systems, in particular the flail and tiller machines are expensive and requires substantial investments, not only for machine costs but also for logistics and maintenance, and actually can only be employed on a fraction of the total mined areas. The logistical problems associated with transporting heavy machinery to remote areas is critical in countries with little infrastructure and resources. Despite these advances, mechanical clearance equipment is of limited capability and it is unlikely, at least in the near term, to meet the minimum $99.6 \%$ effectiveness criteria and safety standards required by humanitarian demining. With this technique, machines often do not destroy all mines in a contaminated area, and AP mines may be pushed on side or buried deeper or partly damaged making them more dangerous. However, to achieve high clearance rate, the most effective way is to use these machines in conjunction with dog teams and/or manual clearance team, which double check an area for remaining mines. Mechanical clearance equipment is expensive and it cannot be used on roadsides, steep hills, around large trees, inside a residential area, soft terrain, heavy vegetation or rocky terrain. Mobility and maneuverability where wheeled vehicles cannot travel efficiently on anything other than flat surfaces, tracked vehicles cannot travel in areas with steep vertical walls, machines in general cannot climb undefined obstacles, and machines cannot in general deform to get through narrow entrances. Also, it is important for such machines to work in a wide range of operational conditions such as, temperature and humidity and the need for protection against dust for engine and crew. In addition, mechanical clearance has its own environmental impact such as erosion and soil pollution. However, a single mechanical mine clearance unit can work faster than a thousand deminers over flat fields. Thus they are cost effective in limited circumstances.

A number of mechanical mine clearing machines have been tested during the past. The general trend goes from "mechanical demining" towards "mechanically assisted demining", adaptable to local circumstances. Some examples of mechanical clearance equipment include but not limited, Vegetation cutters, Flails and Light-Flails, Panther mine clearing vehicle, Armored bulldozer, Ploughs and the rake plough, the M2 Surface "V" mine plow, Earth tillers, Mine sifter, Armored wheel shovel, Mine clearing cultivator, Floating mine blade, Rollers, Mineproof vehicles, Swedish Mine Fighter (SMF), Armored road grader, etc. (US Department of Defense, 1999; Humanitarian Mine Action Equipment Catalogue, 1999; Department of Defense, 2202; Habib, 2002a; Geneva Centre for Humanitarian Demining, 2006).

There is an urgent need to speed up the development to have compact and portable, low cost, technically feasible, fast response, safe, accurate, reliable, and easy to operate mine detector systems with flexible mobile platforms that can be reliably used to detect all types of available landmines and support fast and wide area coverage. Appropriate mine clearance technologies are those inexpensive, rugged, and reliable technical products, processes and techniques that are developed within, or should be transferred for use in mine-affected areas. They are also technologies that are cheap enough to be purchased within the regional economy and simple enough to be made and maintained in a small workshop. We should favor technologies that can be manufactured in mined countries; technologies that are transferable, and which provide employment and economic infrastructure where it is most urgently required.

In addition, vegetation represents a large problem facing demining (mainly in tropical countries) and often poses major difficulties to the demining efforts. The vegetation removal can take up a substantial fraction of the time and for this there is a need to properly mechanized vegetation cutting and removal. These machines should be designed to cut 
down on the time required for demining. In their simplest form, vegetation cutters consist of adequately modified commercial devices (e.g. agricultural tractors with hedge cutters or excavators). There is an urgent need for effective vegetation clearance technology and techniques that avoid detonating mines. Cost effective and efficient clearance techniques for clearing both landmines and vegetation have been identified as a significant need by the demining community

\section{Robotics and Humanitarian Demining}

A portable handheld mine detection approach to sensor movement is slow and hazardous for the individual deminers. Armoured vehicles may not thoroughly protect the occupants and may be of only limited usefulness in off-road operations. Most people in the mine clearance community would be delighted if the work could be done remotely through teleoperated systems or, even better, autonomously through the use of service robots. Remote control of most equipment is quite feasible. However, the benefit of mounting a mine detector on a remotely controlled vehicle should have careful considerations that lead to decide whether the anticipated reduction in risk to the operator justifies the added cost and possible reduction in efficiency. A cost analysis should be made to determine to what extent remote control approach is a valid solution.

To increase mine clearance daily performance by improving productivity and accuracy, and to increase safety of demining operations and personnel, there is a need for an efficient, reliable and cost effective humanitarian mine action equipment with flexible and adaptable mobility, and some level of decision making capabilities. Such equipment should have selectable sets of mine detectors and work to locate and mark individual mines precisely, and at a later stage to neutralize the detected mines. Robotics solutions properly sized with suitable modularized mechanized structure and well adapted to local conditions of minefields can greatly improve the safety of personnel as well as work efficiency, productivity and flexibility. Robotics solution can range from modular components that can convert any mine clearing vehicle to a remote-controlled device, to prodding tools connected to a robotic arm, and to mobile vehicles with arrays of detection sensors and area mineclearance devices. The targeted robot should have the capability to operate in multi modes. It should be possible for someone with only basic training to operate the system. Robots can speedup the clearance process when used in combination with handheld mine detection tools, and they are going to be useful for quick verification and quality control. To facilitate a good robot performance in the demining process, there is a need to employ mechanized systems that are able to remove obstructions that deter manual and canine search methods without severely disturbing soil. Solving this problem presents challenges in the robotics research field and all relevant research areas. Robotics research requires the successful integration of a number of disparate technologies that need to have a focus to develop:

a) Flexible mechanics and modular structures,

b) Mobility and behavior based control architecture,

c) Human support functionalities and interaction,

d) Homogeneous and heterogeneous sensors integration and data fusion,

e) Different aspect of fast autonomous or semi-autonomous navigation in a dynamic and unstructured environment,

f) Planning, coordination, and cooperation among multi robots,

g) Wireless connectivity and natural communication with humans, 
h) Virtual reality and real time interaction to support the planning and logistics of robot service, and

i) Machine intelligence, computation intelligence and advanced signal processing algorithms and techniques.

Furthermore, the use of many robots working and coordinating their movement will improve the productivity of overall mine detection and demining process through the use of team of robots cooperating and coordinating their work in parallel to enable parallel tasks (Gage, 1995; Habib, 1998).

The possible introduction of robots into demining process can be done through surface preparation and marking, speeding-up detection, and mine removal or neutralization. In addition, service robots can be used for minefield mapping too. However, the cost of applying service robot's technologies and techniques must be justified by the benefits it provides. There is no doubt that one of the major benefits would be the safety, by removing the operator from the hazardous area.

It is clear that the development of a unique and universal robot that can operate under wide and different terrain and environmental conditions to meet demining requirements is not a simple task. In the short term, it appears that the best use of robotics will be as mobile platforms with arrays of mine detection sensors and area mine clearance devices. Teleoperations are promising but are limited too, because their remote human controllers have limited feedback and are unable to drive them effectively in real time. There are still some doubts whether such equipment will operate as effectively when the operator is at a long distance, or has been removed altogether. Strangely enough, this is particularly true for urban areas normally full of rubble, while agricultural areas seem to be better, but that is not always true. A possible idea in using robots for demining is to design a series of simple and modularized robots, each one capable of performing one of the elementary operations that are required to effectively clear a minefield. An appropriate mix of such machines should be chosen for each demining task, keeping in mind that it is very unlikely that the whole process can be made fully autonomous. It is absolutely clear that in many cases, the environment to be dealt with is so hostile that no autonomous robot has any chance to be used in mid and short terms. The effort devoted to robotic solutions would be more helpful if it is directed at simple equipment improvements and low-cost robotic devices to provide some useful improvements in safety and cost-effectiveness in the short to medium term.

Several practical difficulties in using robots for mine clearance have been highlighed (Treveylan, 1997). There is little value in a system that makes life safer for the operator but which will be less effective at clearing the ground. Accordingly, a serious evaluation and analysis should be done along with having efficient design and techniques. The high cost and sophisticated technology used in robots which required highly trained personal to operate and maintain them are additional factors limiting the possibilities of using robots for humanitarian demining. In spite of this, many efforts have been recognized to develop effective robots for the purpose to offer cheap and fast solution (Nicoud \& Machler, 1996; Habib, 2001b).

Before applying robotics technology for the mine clearance process, it is necessary to specify the basic requirements for a robot to have in order to achieve a better performance. These requirements include mechanisms, algorithms, functions and use.

a) It is essential to design a robot that will not easily detonate any mines it might cross on its way, i.e, to apply ground pressure that will not exceeds the threshold that sets off the 
mines in question. Ground pressure is recognized as an important constraint on a demining vehicle, because ground pressure is what disturbs the ground and triggers many landmines. If a demining vehicle is to safely traverse a minefield, it must exert as low ground pressure as possible. Preferably this would be lower than the minimum pressure value which would detonate a mine.

b) The robot should be able to cross safely over the various ground conditions. This can be achieved by having adaptable and modular locomotion mechanism both for the mobility and structure. The mechanical structure of the robot should be simple, flexible and highly reliable.

c) The robot must be practical, low purchased cost and cheap to run, small, lightweight, and portable.

d) The robot should have efficient surface locomotion concept that is well adapted to unstructured environment. The design should assure proper balance between maneuverability, stability, speed, and the ability to overcome obstacles.

e) It should employ multi sensors system for detecting and recognizing different mines.

f) It should have suitable mechanism for self-recovery for some levels of the problems that it might face during navigation and searching for mines.

g) Design considerations should be given to have a robot that can resist water, sand, temperature and humidity.

h) The mechanical design of the robot should consider practical technology and should be as simple and low in technology so that anyone can find and replace and possibly make it using locally available materials, such as, bicycle components, bamboo, etc.

i) The robot should work in more than one operational mode such as teleoperated, semiautonomous, and autonomous modes while keeping the deminer out of physical contacts with mine areas. Operator safety should be guaranteed.

j) It should be capable of withstanding explosive blast without suffering major damage. At the minimum the high tech parts of the robot that cannot be replaced locally should be well protected.

k) The robot should be easy to maintain in terms of service and repair by indigenous users. Ease of maintenance is built in at the design stage so that if repair is ever necessary it may be carried out locally without the use of special test equipment or specialized staff. The robots need to be tested and deployed without minimum cost.

1) Sustaining a reasonable power supply to enable the robot to operate for long period.

m) Efficient navigation techniques, with sensor based localization in the minefield, and man-machine-interfaces including the ergonomy of lightweight portable control stations with friendly user interface.

Research into individual, mine-seeking robots is in the early stages. In their current status, they are not an appropriate solution for mine clearance. This is because, their use is bounded by sensing devices and techniques improvements, the difficulties facing automated solutions raised by the variety of mines and minefields, and the variety of terrains in which mine can be found. Examples of such terrains include, dessert, sides of mountains, rocky, forest, rice paddy, riverbanks, plantations, residential areas, etc. Also, robotized solutions are yet too expensive to be used for humanitarian demining operations in countries like Angola, Afghanistan, Cambodia, etc.

Many efforts have been recognized to develop an effective robots for the purpose to offer cheap and fast solutions. Three main directions can be recognized: Teleoperated machines, Multifunctional teleopeated robot, and Demining service robots 


\section{Robotization of Humanitarian Demining}

This section highlights some of the main efforts that aim to robotize the process of humanitarian demining:

\subsection{Teleoperated Machines}

\subsubsection{Light-Flail}

Smaller and cheaper versions of the flail systems are developed with chains attached to a spinning rotor to beat the ground and integrated with remotely controlled, line-of-sight, skid loader chases. The use of light-flails aim to safely clear light to medium vegetation, neutralize AP-mines and UXOs from footpaths and off-road areas, and assist in area reduction of minefield (See Fig. 1). These machines are developed to provide a capability to remotely clear AP mines and proof areas that have been cleared (Humanitarian Demining Developmental Technologies, 1998; Geneva Centre for Humanitarian Demining, 2006). The design of such machines was in particular for dealing with vegetation clearance and tripwires as a precursor to accelerate manual clearance. These flail systems are not designed for heavily vegetated or extremely rough terrain. Some systems can clear AP mines from offroad locations and areas that are not accessible by larger mechanical mine clearing equipment. The light-Flail can defeat bounding, tripwire, fuzzed, and simple pressure AP mines. In addition, these machines have flail clearance depth between $150 \mathrm{~mm}$ and $200 \mathrm{~mm}$ and range of working width between $1.4 \mathrm{~m}$ and $2.22 \mathrm{~m}$. These machines are designed to withstand blasts up to $9 \mathrm{~kg}$ of TNT. They are remotely controlled up to a range of $5,000 \mathrm{~m}$ through feedback sensors and up to 500m away (line-of-sight distance) if it is working in an open space. An armored hood is available to protect these machines against AP mine blasts. Furthermore, there are set of tracks for installation over the tires when working in soft soil conditions to improve traction.

Different machines made by different manufacturers with almost similar concept are available and have been used in real minefields. Some of these are (Humanitarian Demining Developmental Technologies, 1998; Geneva Centre for Humanitarian Demining, 2006; Croatia Mine Action Centre, 2002; Danielsson et al., 2003; Danielsson et al., 2004; Leach, 2004):

a) Two machines of Armtrac 25 are in service with the UK Ministry of Defense with no information for actual usage in a real minefield,

b) More than 110 Bozena machines have been produced. These machines have been, or are currently, in service in Afghanistan, Albania, Angola, Azerbaijan, Bosnia and Herzegovina, Cambodia, Czech Republic, Eritrea, Ethiopia, Iraq, Kenya, Kosovo, Lebanon, The Netherlands, Poland, Slovakia, Sri Lanka, and Thailand,

c) The Compact Minecat 140 was developed in 2001 as a direct follow-up improvement of the MineCat 230 and has not yet been used in real minefields,

d) There are 62 MV-4 light flails have been purchased by various organizations/demining companies. Some of the organizations are, US Army (21 units), Swedish Army (5 units), Croatian Army (2 units), Irish Army (2 units), International Mine Action Training Centre (IMATC) Kenya (1 unit), Croatian Mine Action Centre (CROMAC) (4 units), Iraqi National Mine Action Authority (4 units), Norwegian People's Aid (NPA) (3 units), Swiss Foundation for Mine Action (FSD) (5 units), etc,

e) Mini-Flails have been tested extensively in Kuwait, Bosnia, Kosovo, and Jordan. Currently, Six Mini-Flails are deployed today in the Balkans, and four systems are deployed in Afghanistan. The new version 'Mini-Deminer' incorporates improvements to the problems associated with 
the U.S. Army's original Mini-Flail identified during field evaluations. Development testing of the Mini-Deminer took place during the spring and summer of 1999, and

f) There is no information available by the manufacturer on the actual usage of Diana 44T machine in real minefields.

All light flail machines are featured by, small and compact in size, ease to transport on a light trailer, remotely controlled, ease of maintenance and repair, powerful engine with efficient cooling system, etc.

Light flail machines have difficulties to operate with precision from a long distance (this applies to all remotely controlled machines), as they require line of sight operation with suitabel feedback. The ground flailing systems creates large dust clouds and the high vegetation will restrict operator's view on the machine. They also exhibit difficulty in flailing in soft soil, and can inadvertently scatter mines into previously cleared areas. All machines are not intended to be used in areas where AT mines are present, and they may not be usable in steep or rocky terrain.

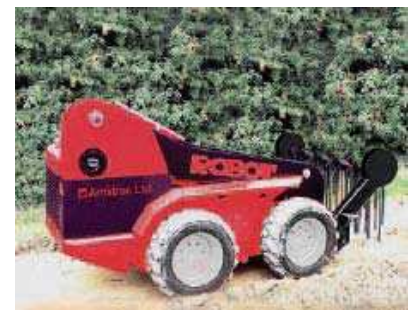

(a) Armtrac 25. Kingdom)

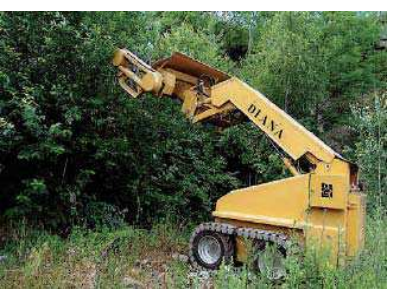

(d) Diana 44T

(Hontstav S.R.O., Slovak Republic)

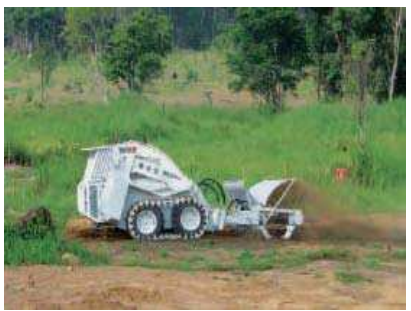

(b) Bozena 4

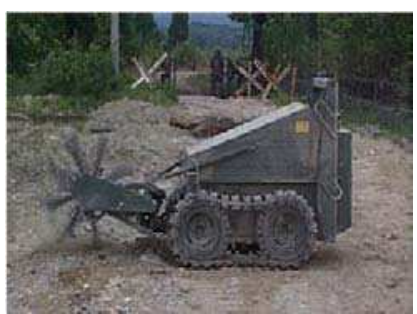

(c) Mini-flail.

(WAY Industry J.S. Co, (US Department of Slovak Republic)

Defense)

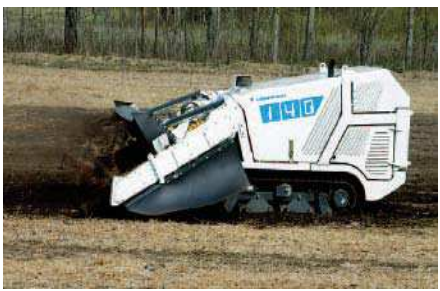

(e) Minecat 140 .

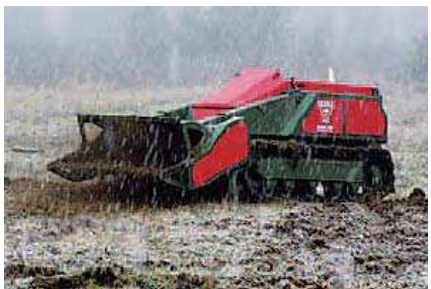

(Norwegian Demining

(f) The MV-4.

Consortium)

Fig.1. Different types of light flails in action.

\subsubsection{Remotely Operated Vehicles (Kentree Limited)}

Kentree Limited has been designing and manufacturing variety of remotely operated vehicles. Hobo was the early developed vehicle and it has a reasonable maneuverability, 6 robust wheels to allow carriage goes over obstacles and through water. Many updates have been introduced to meet the continued requirements in Explosive Ordnance Disposal (EOD)/Improvised Explosive Device Disposal (IEDD) applications and those required in battle zones, nuclear, chemical or fire fighting situations. The most apparent are the articulating rear axle and the Radio Control. The tracked chassis has a front ramp section which lowers to provide a variable footprint. With this 
additional traction, the vehicle negotiates slopes, stairs and steps with ease. Hobot is the track version of Hobo for use in areas where tracks are the required option as in certain nuclear or chemical environments. The dimension of Hobo L3A15 is $\mathrm{L}=148.3 \mathrm{~cm}, \mathrm{~W}=70.76 \mathrm{~cm}$ and $\mathrm{H}=$ $88.81 \mathrm{~cm}$, the vehicle weight when empty is $228 \mathrm{~kg}$, the payload of the arm is $30 \mathrm{~kg}$, and the maximum speed is $4 \mathrm{~km} / \mathrm{h}$. Other teleoperated vehicle developed by Kentree includes, Vegabond, Rambler, Max, Brat, Tramp and Imp.

One of the latest additions to the Kentree family of vehicles is the "Thrasher" mobile vehicle designed for the purpose of demining. Kentree and the Irish armed forces are developing Thrasher as cost-effective solution for demining operations. Thrasher is small and it is capable of dealing with narrow laneways. The remotely controlled route clearance flail system is aimed at clearing a 4 feet wide path of booby traps and AP mines to allow safe personnel passage. The vehicle can also be fitted with an offset rear flail attachment, to increase the beat area to 8 feet. This will allow the access of small transport vehicles. The ROV can be controlled via secure radio link from the front passenger seat of a jeep by means of a laptop control console with video feed to virtual reality goggles. Alternatively, it may be operated by backpack style system with hand control for foot-mounted demining operations. No information for demining testing and evaluation is available. Figure 2 shows Hobo, Hobot and Thrasher robots.

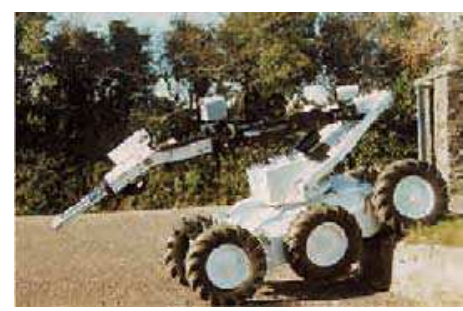

(a) The wheeled Hobo.

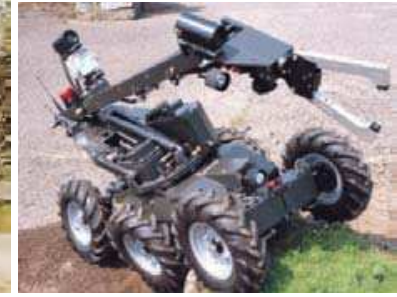

(b) The wheeled Hobo.

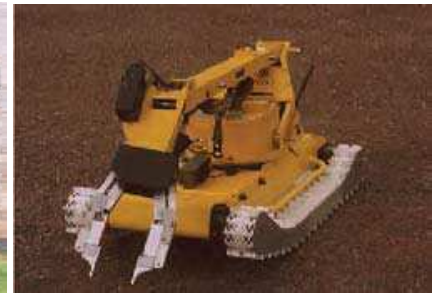

(c) the tracked Hobot.

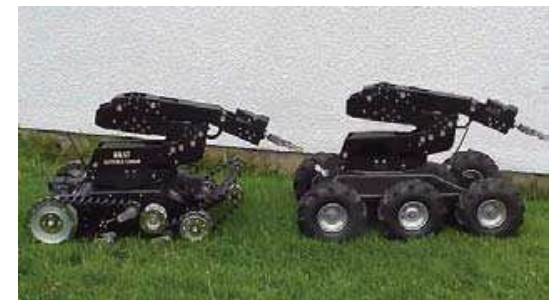

(d) The Brat.

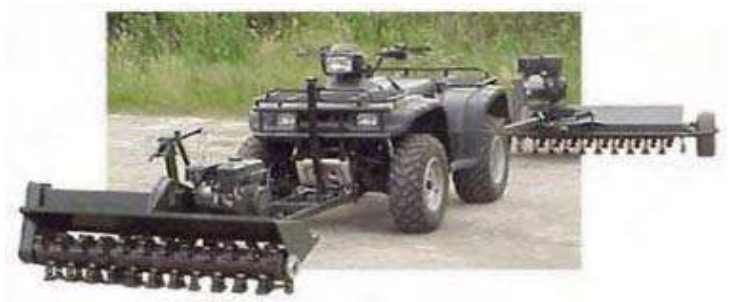

(e) Thrasher.

Fig. 2. Remotely operated vehicles from Kentree.

\subsection{Multi Functional Teleoperated Robots}

\subsubsection{Demining mobile robot MR-2 (Engineering Service Incorporation (ESI))}

MR-2 is an off-road, modular, teleoperated, multi-sensor mobile platform designed to detect landmines, including those with minimal metal content, and UXO. MR-2 is a modular system comprising a remotely operated vehicle (ROV), control unit, MR-1 robotic arm for scanning, laser range camera and metal detector (ESI, 2003). MR-2 uses only one metal detector (of-the-shelf unit that can be easily detached and used manually), and combines the latest laser/ultrasonic based terrain imaging technology that allows the metal detector to 
adaptively follows the terrain surface while avoiding obstacles. MR-2 can perform neutralization of landmines using MR-1 arm under the supervision of remotely located operator. MR-1 is a ragged modular dexterous robotic arm (See Fig. 3). The ROV is capable of turning 360 degrees in $1.5 \mathrm{~m}$ wide hallway, traversing virtually any terrain up to 45 degrees in slope, over $70 \mathrm{~cm}$ ditches, curbs, etc. It operates either with wheel or track and quick mount/dismount tracks over wheels. MR-2 works at high-speed scanning (up to 5 $\mathrm{km}$ /hour) with wide detection path (about $3 \mathrm{~m}$ ). The MR-2 is an autonomous mine detection system that operates at high speed with minimum logistic burden. The MR-2 is a high cost and heavy robot that is designed to search for mines in terrain with rich vegetation stones, sand, puddles and various obstacles. The open architecture of MR-2 allows expansion with generic and custom-made modules (semi-autonomous navigation, preprogrammed motion, landmine detection, etc.). Sensor payloads can be extended to include a metal detection array, an infrared imager, GPR and a thermal neutron activation detector. Data fusion methodologies are used to combine the discrete detector outputs for presentation to the operator. No evaluation and testing results in relation to demining are available.

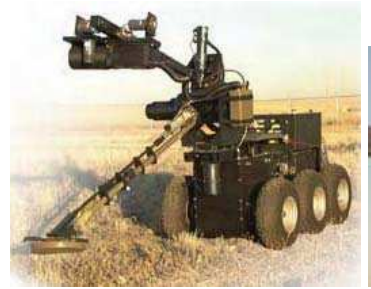

(a) The MR-Robot.

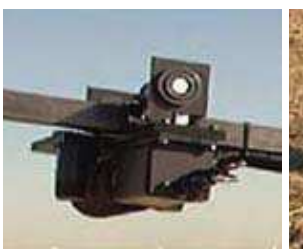

(b) Laser/US imaging.

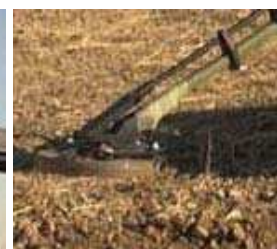

(c) Metal detector.

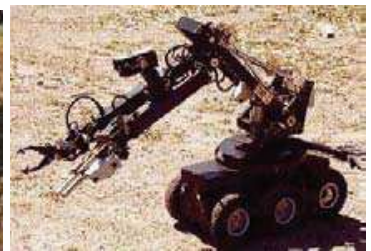

(d) MR-2 with MR-1.

Fig.3. The MR-2 demining mobile robot.

\subsubsection{Enhanced Tele-Operated Ordnance Disposal System (ETODS)}

(OAO Corporation, Robotics Division)

The Enhanced Teleoperated Ordnance Disposal System (ETODS) is a remotely controlled teleoperated system that is based on a modified commercial skid loader with a modular tooling interface which can be field configured to provide the abilities to remotely clear light vegetation, detect buried unexploded ordnance (UXO) \& landmines, excavate, manipulate, and neutralize UXO \& landmines mines, to address the need of various mechanical clearance activities associated with humanitarian demining (Eisenhauer et al., 1999). ETODS has an integrated blast shield and solid tires.

ETODS includes a heavy vegetation cutter and a rapidly interchangeable arm with specialized attachments for landmine excavation. Attachments include an air knife for excavation of landmines, a bucket for soil removal, and a gripper arm to manipulate certain targets. Remote control capability combined with a differential GPS subsystem and onboard cameras enable the system to navigate within a minefield to locations of previously marked mines. Mines or suspicious objects already marked or identified with GPS coordinates can be checked and confirmed with an on-board commercial detector and then excavated with a modified commercial backhoe, an air knife, excavation bucket, or gripper attachment. ETODS was developed and configured for the US DoD humanitarian demining research and development Program starting in 1995. It has been through many field test 
activities, and they found it suitable for use in humanitarian demining (HD) operations. The HD issues that have been evaluated include accuracy, repeatability, and feasibility of usage in remote environments. In relation to vegetation cutting, three attachments have been tested. One front mounted bush hog and two side mounted boom mowers. In this case, the HD issues that have been evaluated include the ability to cut dense undergrowth, the proper preparation of the ground for ensuing detection activities, and the ability of the operator to effectively and efficiently clear an area under remote control. As for commercial backhoe that can be field mounted to the ETODS, the HD issues that have been evaluated include the effectiveness and efficiency of locating and excavating mines, operator training requirements, inadvertent detonation rates, techniques for deeper excavations, techniques to identify mines and their status (e.g. booby trapped), and blast survivability/repair. A chain flail attachment converts the ETODS into a system capable of clearing AP mines through detonation, and for this case the HD issues that have been evaluated include the minimum sized mine cleared, depth of clearance, effectiveness of clearance, speed of clearance, and blast survivability/repair. During testing, ETODS was subjected to a $12 \mathrm{lb}$. TNT blast replicating an AT mine detonation. ETODS drove away with field repairable damage. ETODS has proven effective in detonating M14 AP mines and is survivable through repeated $1.0 \mathrm{lb}$. TNT detonations (OAO-Robotics, website). TODS provides safe, effective delivery of tools necessary for the clearance of landmines and UXO. ETODS is simple, rugged, and can provide a high technology indigenous demining capability in remote environments.

The ETODS has completed operational field evaluations in Jordan and Egypt, where it was found to have several significant limitations that make it less than suitable for humanitarian demining operations (Figure 4 shows the ETODS is action). These include the tendency to become mired in mud or desert sand conditions, as well as the requirement for significant training to develop teleoperation skills (Department of Defense, Development Technologies, 2001-2002).
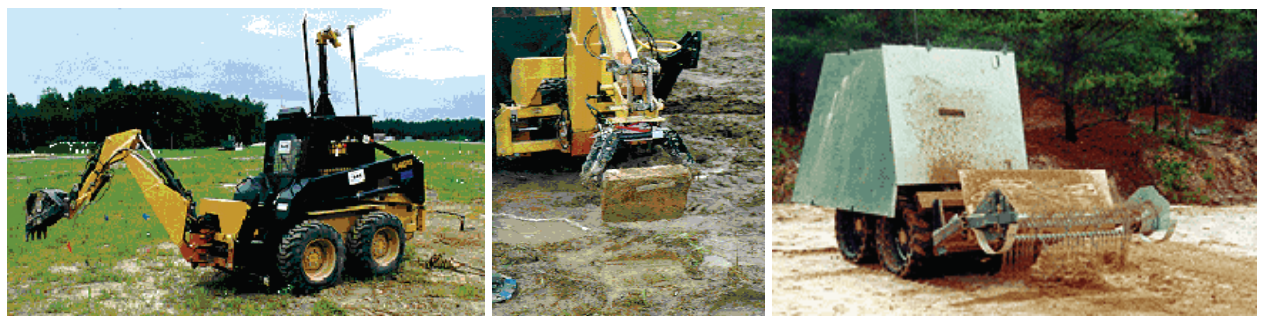

Fig. 4. The ETODS in action.

\subsubsection{TEMPEST. (Development Technology Workshop (DTW)}

TEMPEST is designed to safely clear light to medium vegetation, clear tripwire fuzed mines, and assist in area reduction as a precursor to accelerated manual clearance. DTW began production of the TEMPEST Mk I in 1998-99 in which it was designed purely as a vegetation-cutting device, and currently, the TEMPEST Mk V is in production. The TEMPEST Mk V is a remotely controlled, lightweight multi-tool system with vegetation cutting and trip wire clearing abilities (See Fig.5).

TEMPEST is a low cost, small size and light weight radio controlled AP mine blast-protected multi purpose ground based system. These features aim to ease of transport and agility over difficult terrain. It can support a variety of interchangeable clearance heads to clear vegetation, 
removal of metal fragmentations by using large and small magnets for the removal of metal fragmentations, engage the ground with flail head, and neutralize tripwires, etc. It is designed to clear AP mines from off-road areas inaccessible to large-area mine clearers. The TEMPEST system consists of a diesel powered hydraulically driven chassis, a radio control subsystem, and each of its four hydrostatic wheels is driven by an independent motor to improve maneuverability. The wheels are easy to remove, repair and replace. The TEMPEST also has a 1.2-meter wide horizontal chain flail with vegetation cutting tips, and an adaptable flail head with hydraulic feedback system that can sense the load on the flail, i.e., the operator can set the speed control to maximum and the TEMPEST will automatically control its cutting rate and drive speed, and progress accordingly. The TEMPEST's ground engagement flail is designed to dig into the soil in order to destroy or expose mines by cutting $10 \mathrm{~cm}$ deep into the ground to initiate surface and sub surface mines at that level. Its V-shaped chassis and sacrificial wheels minimize damage from anti-personnel mine or UXO detonation and provide some protection against anti-tank mines. TEMPEST's vertical axis "slasher" is capable of cutting through difficult vegetation such as bamboo and vines and its large magnetic array is capable of extracting ferrous material from the ground. It is able to clear up to $200 \mathrm{~m}^{2} / \mathrm{h}$ of light vegetation $(500 \mathrm{~mm}$ tall thick grass) and to cut $100 \mathrm{~mm}$ tree in 3-4 minutes. TEMPEST is featured by ease of operation, maintenance, and repair.

TEMPEST is inexpensive to purchase and operate relative to other vegetation clearance systems. Currently, the TEMPEST is produced in Cambodia as well as the United Kingdom, thus representing a regional capability in Southeast Asia (Department of Defense, Development Technologies, 2001-2002).

The TEMPEST is an excellent example of how an operational evaluation can lead to improvements that realize the potential of a prototype design. The early prototype of TEMPEST underwent extensive tests in Cambodia for AP and AT mines. The TEMPEST began an operational evaluation in Thailand in January 2001. Although it was effective at clearing vegetation in mined areas, Thai operators identified overheating problems. The unit's promising performance warranted the investment of funds to improve the system. TEMPEST Mk IV has been tested in Mozambique during 2003. The actual use of TEMEST systems and the continuous evaluation results in having TEMPEST Mk V as a reliable system with more speed and engine power capacity compare to the previous versions. As evaluated by the manufacturer, the hydraulic hoses are vulnerable to fragmentation attacks, and the machine is not intended to be used in areas where AT mines are present. As evaluated by deminers, the TEMPEST requires the operator to maintain direct line of sight with the system from a minimum of 50 meters and the operator can only be this close if behind the system's portable shield. This poses a problem in dense vegetation or rolling terrain. The TEMPEST has limited traction on wet muddy terrain due to the steel wheels clogging with mud. The machine has the ability to clear both mines and vegetation, even though with limitations. The ground flailing system creates large dust clouds. The view of the operator on the machine can be restricted and the air filters can be clogged (Leach et al., 2005).

Currently, there are now 25 machines operating in Angola, Bosnia, Cambodia, DR Congo, Mozambique, Sri Lanka and Thailand. The TEMPEST is currently used by seven demining organizations around the world (Geneva Centre for Humanitarian Demining, 2006). The new TEMPEST Mk VI will mitigate the highlighted problems by use of a new remote control system and the integration of tracks in place of the steel wheels to enable the vehicle to operate on most soil conditions and terrains. 

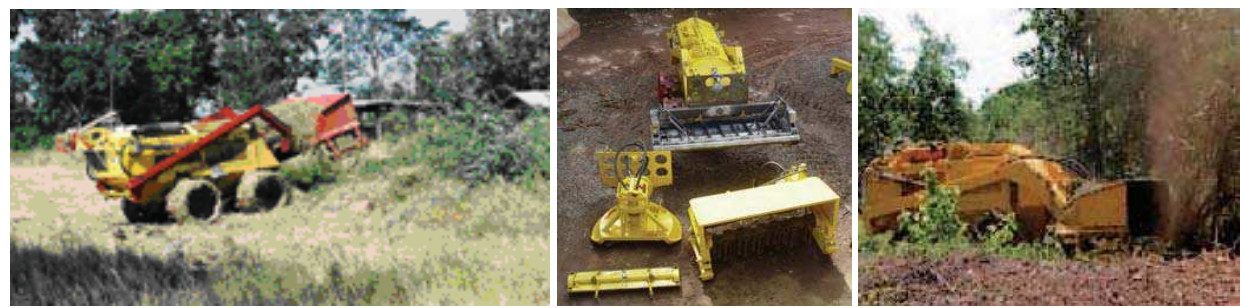

Fig. 5. Tempest during operational field evaluation.

\subsection{Demining Service Robots}

\subsubsection{Three wheels Dervish robot (University of Edinburgh/ UK)}

Dervish was originally designed to bypass the problem of mine detection by deliberately rolling over the mines with mine-resistant wheels. The Dervish is a remotely-controlled wheeled vehicle designed to detect and detonate AP mines with charge weights up to 250 grams that is equivalent to the largest size of AP mines. It is a three-wheeled vehicle with wheel axles pointing to the center of a triangle. The weight of Dervish closely emulates (a little more than) the ground loading of a human leg (Salter\& Gibson, 1999). But, becasue of its low weight, Dervish will not explode AT mines. The wheels are placed at 120 degrees from each other. The Dervish drive uses three variable-displacement computercontrolled hydraulic pumps driven by a $340 \mathrm{cc}$ Honda engine, and controlled by a microprocessor to drive a Danfoss hydraulic motor at each wheel. The steel wheels weight about $80 \mathrm{~kg}$ and are 4-6 cm thick. Due to the position of the wheels, if all Dervish wheels were driven at the same speed then it would merely rotate about its center and make no forward progress. However, carefully timed, small, cyclical variations of wheel speed make the Dervish wheels describe spirals and progressively translate in a chosen direction so that every point in its path is covered, twice, by a loading of about $90 \mathrm{~kg}$ in a pattern of overlapping circles. Repeatedly locking one wheel and driving the other two wheels spins the machine through 120 degrees about the locked one and allows traversing. Dervish has a very open steel frame with all members oblique to the path of blast fragments. It effectively has a zero-radius turning circle. A wide path can hence be stamped by radiocontrol. Figure 6 shows Dervish and illustrates the spiral movements of the robot. It is claimed by the designer that in case of mine explosion, the wheel and the compact hydraulic motor should resist. The tetrahedral structure linking the three wheels and the central power source will be easily repaired.

In normal mine-detonating mode, the Dervish advances at about one meter a minute, a rate set by the requirement that there should be no mine-sized gaps between its wheel tracks, i.e, covering the ground at intervals of only $3 \mathrm{~cm}$ to avoid any mine-sized gaps between its wheel tracks. A possible change to the wheel design may increase this by a factor of three. With its design structure, it can sweep a 5 meter wide track with a possible coverage of 300900 square meters per hour. The machine is designed for the clearance of agricultural land. It can operate on open, uneven, or moderately sloping ground. All the electronic equipment is fitted into steel tubes made from old nitrogen bottles with carefully-machined O-ring seals and uses military specification connectors. The Dervish can carry a metal detector placed in a thorn-resistant protective shroud with the sensor head just inboard of the wheel radius at 60 degrees from a wheel. Other sensors for non-metallic targets especially ones that respond 
to explosives in gram quantities have not been introduced. In a test with a $10 \mathrm{~kg}$ charge, damage was confined to one corner while the axle and bearings from that test are still in use. The repair cost would be a few hundred dollars. The main limitations of this robot are: not suitable for difficult terrain, hard to navigate, blast-resistant wheels are unsuited to very soft ground, and the inability of the robot with its particular wheel configuration and available power to have enough torque to get out of a hole after a mine blast. This has prompted the team to work on a future complementary design aimed purely at sensor movement with no mine detonation.
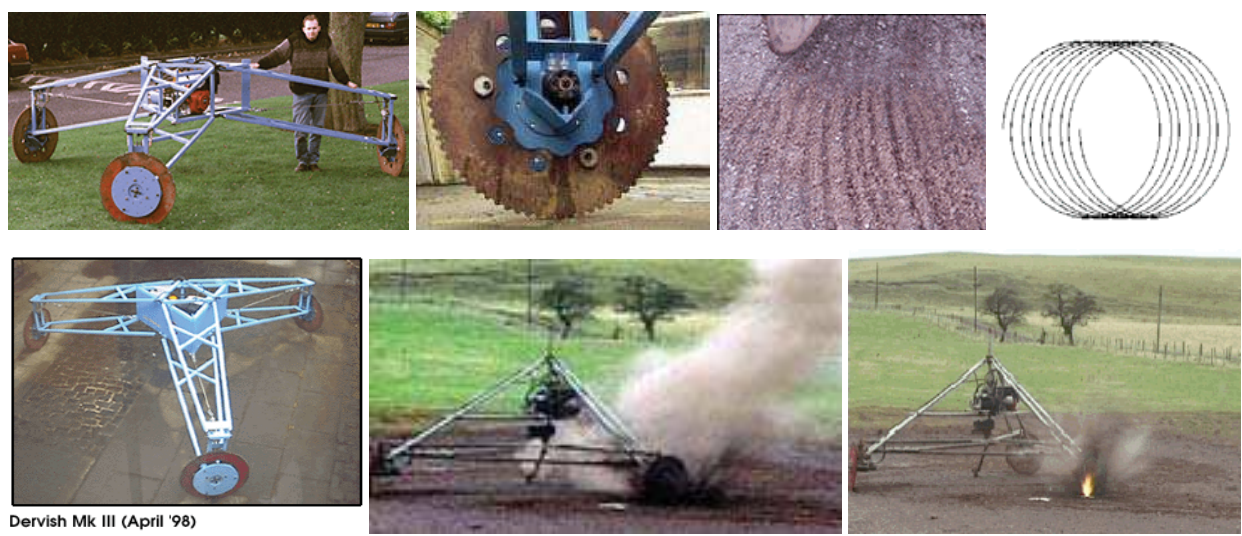

Fig. 6. The DERVISH robot.

\subsubsection{PEMEX-BE (PErsonal Mine EXplorer) (LAMI-EPFL/Switzerland)}

Pemex is a low cost solution for carrying a mine sensor and exploring automatically an area. Pemex is a two-wheeled robot built uses mountain bicycle wheels and aims to investigate cross-country navigation and to evaluate sensors for the detection of AP mines (See Fig. 7). It is a lightweight vehicle (less than $16 \mathrm{~kg}$ ) and exerts a maximum force of $6 \mathrm{~kg}$ on the ground that is not supposed to trigger any of AP mines it detects. The wheels are driven by 90W DC motors from Maxon with 1:72 reductors aiming to give to the robot a maximum speed of $6 \mathrm{~km} / \mathrm{h}$ power it. When searching for mines the Pemex head oscillates right and left in a zigzag movement covering a 1-meter wide path (Nicoud \& Habib, 1995; Nicoud, 1996). The on-board 68331 microprocessor permits autonomous or teleoperated navigation. Polaroid and Sharp PSD ultrasonic sonar sensors detect obstacles. The mine sensor head currently contains as a metal detector. It is intended to be integrated a combination of a metal detector (MD) and a ground-penetrating radar (GPR) that have been evaluated in real minefield. The ERA radar was selected in early 1996, and different metal detectors brands from (Schiebel-Austria, Foerster-Germany and Ebinger-Germany) were used and tested (Nicoud at el., 1998). Pemex has rechargeable batteries that can provide 60 minutes of autonomy.

Mined terrain is often overgrown with dense vegetation. Pemex-BE's mountain bike wheels allow it to move in high grass. With climbing cleats mounted on its wheels, Pemex-BE can climb irregular slopes of $20^{\circ}$ to $30^{\circ}$. It can also climb stairs. The wheels go first when climbing to prevent the sensor package leaving the ground. Pemex is equipped with optional water wings that enable it to float and swim. This allows it to operate in 
environments such as rice paddies and, on land, reduces the pressure on the ground when searching for very sensitive pressure-triggered mines. For transport, the wheels can be removed and attached to the sides of the main chassis. All components can be packed and easily carried by one person.
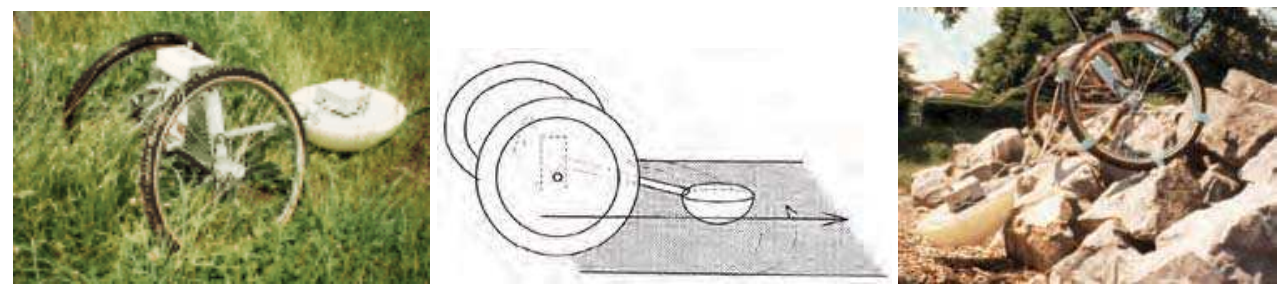

Fig. 7. PEMEX - BE (PErsonal Mine EXplorer).

\subsubsection{Shrimp Robot (EPFL/Switzerland)}

As part of the field and space robotics activities at the Autonomous Systems Lab (ASL) of EPFL-Switzerland, an innovative robot structure has been developed. The first prototype is called the "Shrimp Robot". Shrimp is a high mobility 6-wheels mobile platform. One wheel is front-mounted on an articulated fork, one wheel in rear directly connected to the body and two wheels are mounted on each of two lateral bogies. The total weight of this first prototype is $3.1 \mathrm{~kg}$ including $600 \mathrm{~g}$ of batteries and a $1.75 \mathrm{~W}$ DC motor powers each wheel. The dimensions are L $60 \mathrm{~cm} \times W 35 \mathrm{~cm} \times \mathrm{H} 23 \mathrm{~cm}$; the ground clearance is $15 \mathrm{~cm}$. Shrimp as a new mobile platform shows excellent off-road abilities overcoming rocks even with a single bogie. Shrimp adapts its structure purely passively during motion to insure its stability. This allows very simple control strategy as well as low power consumption. The secret of its high mobility lies in the parallel architecture of the front fork and of the bogies ((Estier et al., 2000a; Estier et al., 2000b). With its passive structure, Shrimp does not need to actively sense obstacles for climbing them. Instead, it simply moves forward and lets its mechanical structure adapt to the terrain profile. With a frontal inclination of 40 degrees, Shrimp is able to passively overcome steps of twice its wheel diameter, to climb stairs or to move in very rough terrain. Shrimp has not been used yet in demining operation, but it can be considered an attractive candidate because of its welladapted locomotion concept and the excellent climbing and steering capabilities that allow high ground clearance while it has very good stability on different types of rough terrain. In May 2001, the developer announced version 3 of the robot, Shrimp III (See Fig. $8)$. This version is powered by 6 motors integrated inside the wheels and steered by two servos. This robot is able to turn on the spot. It is built in anodized Aluminium and it is equipped with modular electronics.
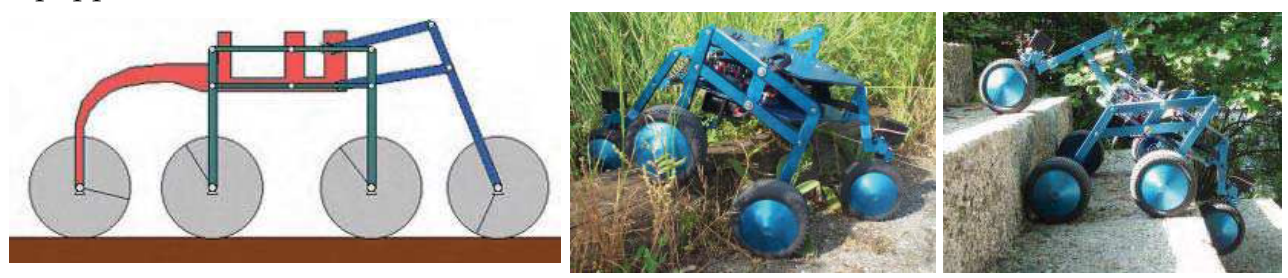

Fig. 8. The Shrimp III Robot. 


\subsubsection{Automatic Mechanical Means of Manual Land Mine Detection}

The aim is to design an automated, single or multiple-prodding device that can be mounted installed in front of a remotely controlled all terrain vehicles. In this regards, at the suggestion of The Defence Research Establishment Suffield (DRES), the 1996 senior design project the University of Alberta was to design innovative mechanical method to detect nonmetallic landmines (Fyfe, 1996). The developed design tries to emulate and multiply the performance of manual prodding done by human operator. The design consists of an automated and hydraulically actuated multiple-prodding device designed to be mounted either in front of a BISON armoured personnel or in front of a remotely controlled all terrain vehicle called ARGO. The detection unit consists of a frame, traversing rack and multiple probes. Each of the 41 or 8 probes (depending on the design) used to penetrate the ground, is individually mounted on a hydraulic cylinder (See Fig.9.). The hydraulic fluid pressure in each cylinder is continuously monitored by a computer data acquisition system. When the probe strikes the soil or a solid object, the pressure in the cylinder rises in proportion to the force on the probe. Once this pressure rises above a threshold value, a solid object is determined to be present. A solenoid valve controlled by the computer releases the pressure in the cylinder, thus stopping the probe from further motion. This valve is quick enough to stop the cylinder in order to prevent the accidental detonation of the suspected mine. Based on the probe separation distance, this system ensures that no landmine is going to be missed by passing between the probes.

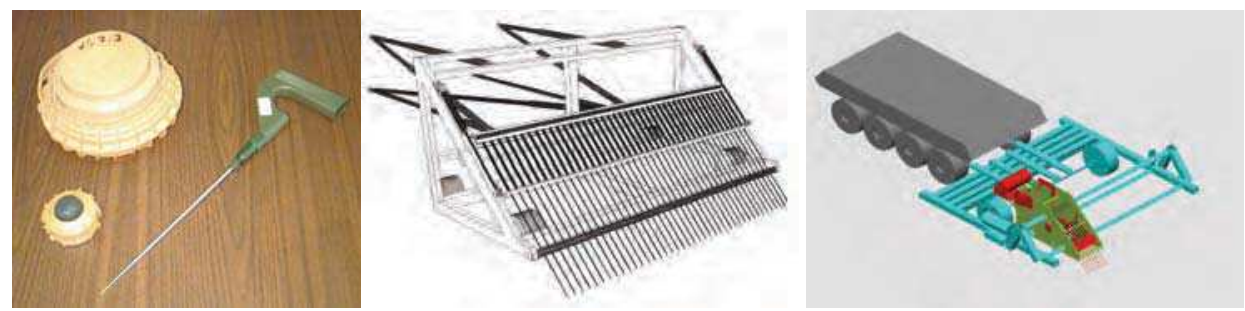

Fig. 9. The design of multiple mechanical means of manual prodding.

A similar approach has been developed (Dawson-Howe \& Williams, 1997). They have assembled a lab prototype, as shown in Fig. 10, intended to demonstrate the feasibility of automatic probing using on an $\mathrm{XY}$ table for the motion (to be fixed on a mobile platform at a later stage), together with a linear actuator, a force sensor and a sharpened steel rod. Probing test was done on an area of $50 \mathrm{~cm} \times 50 \mathrm{~cm}$ and the probing was done at an angle of 30 degrees.

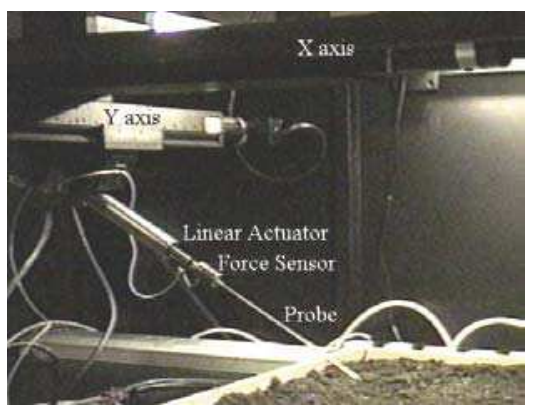

Fig. 10. A laboratory prototype of a single mechanical means of manual prodding. 


\subsubsection{AMRU and Tridem (I and II) (Belgium HUDEM)}

The Belgian joint research program for HUmanitarian DEMining (HUDEM) aims to enhance mine detection by a multi-sensor approach, speed up the minefield perimeter determination and map the minefields by robotic platform. Several mobile scanning systems have been developed, such as the AMRU (Autonomy of Mobile Robots in Unstructured environments) series 1-4, have been modified from previously developed walking mobile robots by Belgium Royal Military.

One of the main purposes of developing such robots was to achieve low-cost machines. In order to meet this constraint, simple mechanical systems for the legs were used and high cost servomotors were replaced by pneumatic and other actuation systems. A simple but robust digital control was implemented using industrial PLCs for the early versions. AMRU-1 is a sliding robot actuated by rodless pneumatically cylinders with the capacity to have $4^{*} 90$ degree indexed rotation. When the metal detector detects something, the robot stops and an alarm is reported to the operator. The robot is equipped with a detection scanner. This robot has poor adaptability to irregular terrain with limited flexibility. AMRU 2 is a six-legged electro-pneumatic robot. Each leg has 3 degrees of freedom rotating around a horizontal axis allowing the transport/transfer phase, a rotation around a horizontal axis used for the radial elongation of the legs and a linear translation allowing the choice of the height of the foot. The first two dofs are obtained by use of rotating double acting pneumatic motors plus double acting cylinders. Other versions have been developed (AMRU 3 and 4) but they are still waiting for testing. The next generation AMRU 5 has 6 legs.

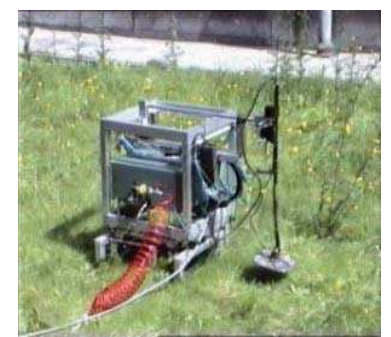

(a) AMRU1

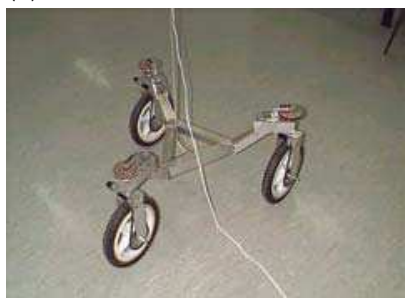

(d) Tridem I

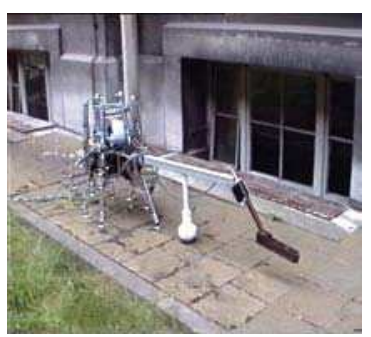

b) AMRU2

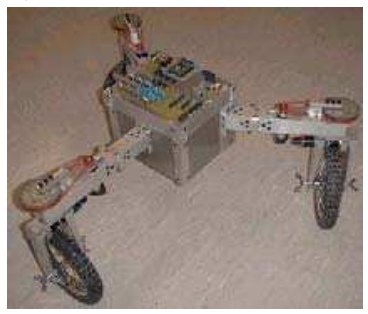

(f) Tridem II

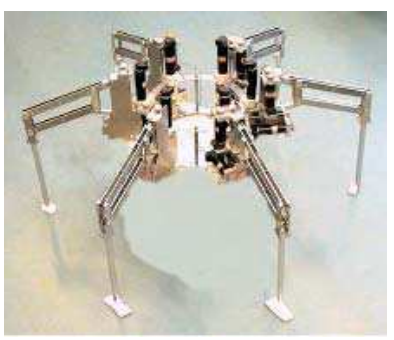

(c) AMRU 5

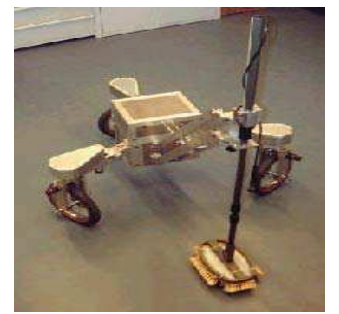

(g) Tridem II with Metal Detector

Fig. 11 Different versions of AMRU and Tridem robots.

In order to obtain a better mobility, the Tridem robot series have been developed. This series of robots has been equipped with three independent modular drive/steer wheels. Each wheel has 2 electrical motors. A triangular frame connects the wheels. This frame supports holding the control electronics and the batteries. The robot has been design to have a $20-\mathrm{kg}$ payload and a speed of $0.1 \mathrm{~m} / \mathrm{sec}$. Two versions of this robot have been 
developed (Tridem I and II). Figure 11 illustrates different versions of AMRU and Tridem robots.

\subsubsection{WHEELEG (University of CATANIA, Italy)}

Since 1998, the WHEELEG robot has been designed and built for the purpose to investigate the capabilities of a hybrid wheeled and legged locomotion structure in rough terrain (Muscato \& Nunnari, 1999; Guccione \& Muscato, 2003). The main idea underlying the wheeled-legged robot is the use of rear wheels to carry most of the weight and front legs to improve surface grip on climbing surface and overcome obstacles (See Fig. 12). This robot has two pneumatically actuated front legs with sliding motion, each one with three degrees of freedom, and two rear wheels independently actuated by using two distinct DC motors. The robot dimensions are Width $=66 \mathrm{~cm}$, Length $=111 \mathrm{~cm}$, and Height $=40 \mathrm{~cm}$. The WHEELEG has six ST52E301 Fuzzy microcontrollers for the control of the pistons, two DSP HCTL1100 for the control of the wheels and a PENTIUM $200 \mathrm{MHz}$ microprocessor for the global trajectory control and the communications with the user. Preliminary navigation tests have been performed showing that WHEELEG cannot only walk but also run. During walking, the robot can overcome obstacles up to $20 \mathrm{~cm}$ high, and it can climb over irregular terrain. Possible applications that have been envisaged are humanitarian demining, exploration of unstructured environments like volcanoes etc. The robot mobility and maneuverability is limited, no demining sensors have been used, and no demining testing and evaluation has been reported.

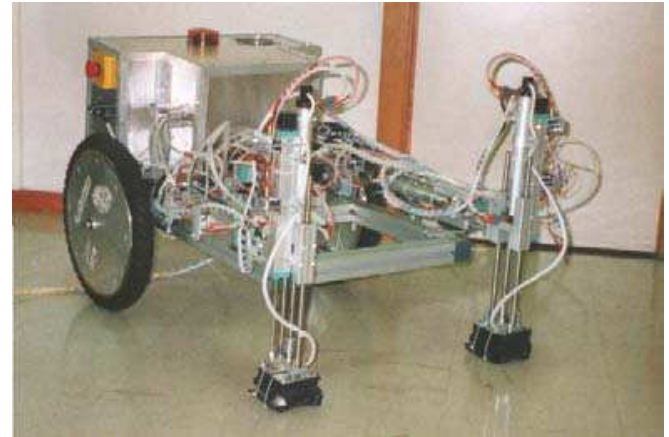

(a) WHEELEG prototype

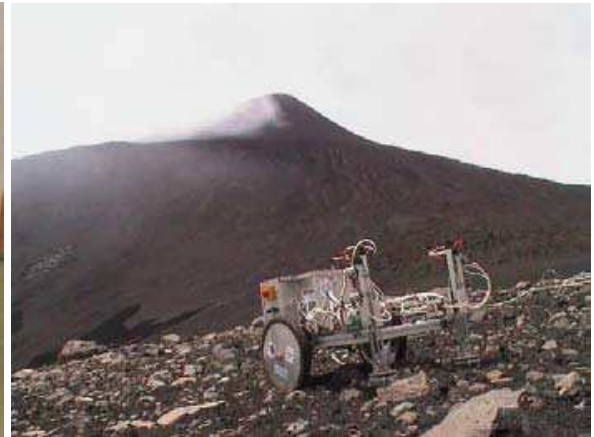

(b) WHEELEG tested on Etna volcano

Fig. 12. The WEELEG Robot.

\subsubsection{Spiral Terrain Autonomous Robot (STAR)}

(Lawrence Livermore National Laboratory (LLNL)

An autonomous vehicle has been developed for versatile use in hostile environments to help reduce the risk to personnel and equipment during high-risk missions. In 1996 LLNL was in the process of developing the Spiral Track Autonomous Robot (STAR), as an electromechanical vehicle that can be fitted with multiple sensor packages to complete a variety of desired missions. STAR is a versatile and manoeuvrable multi-terrain mobile robot that can to be used as an intelligent search and rescue vehicle to negotiate fragile and hostile environments (Perez, 1996). STAR can help with search and rescue missions after disasters, or explore the surfaces of other planets (See Fig. 13). 
Although four-wheel and track vehicles work well, they are limited in negotiating saturated terrain, steep hills and soft soils. The two key mechanical components in the structure of STAR are the frame assembly and the two Archimedes screws. The mechanical frame is made of hollow aluminum cylinders welded together with an aluminum faceplate on each end. The second key mechanical component of the STAR is the screw drive The STAR rolls on a pair of giant Archimedes screws (one left-hand and one right-hand) that serve as the drive mechanism in contact with the local environment to propel itself along the ground. The screws take advantage of ground forces. Rotating the screws in different rotational combinations causes the system to instantly translate and/or rotate as desired in four possible directions, and to turn with a zero turning radius. When they rotate in opposite directions, the robot rumbles forward. When they rotate in the same direction, it scuttles sideways, and when one screw turns while the other holds still, the screw-bot deftly pirouettes. Versatility in directional travel gives the system flexibility to operate in extremely restricted quarters not accessible to much larger pieces of equipment. Furthermore, the Archimedes screws give the vehicle enough buoyancy to negotiate saturated terrain. In water, the hollow screws float and push like propellers. The STAR is compact, measuring 38 inches square and 30 inches high; it has a low centre-of-gravity allowing the system to climb steep terrains not accessible to other hostile environment hardware.
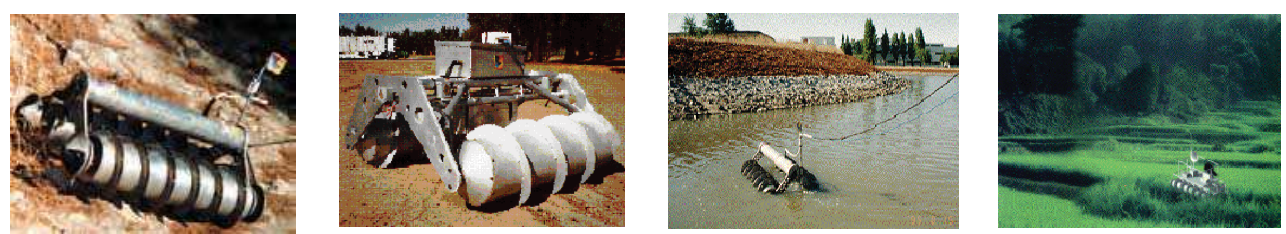

Fig. 13. The STAR robot in different situations.

The STAR is also equipped with a complete on-board electronic control system, data/video communication links, and software to provide the STAR with enough intelligence and capabilities to operate remotely or autonomously. During remote operation, the operator controls the robot from a remote station using wireless data link and control system software resident in a laptop computer. The operator is able to view the surrounding environment using the wireless video link and camera system. Remote operation mode is desirous when personnel must enter an unsecured hostile environment that may contain nerve gases, radiation, etc. Ultrasonic sensors are mounted around the external perimeter of the robot to provide collision-avoidance capabilities during remote and autonomous operations. All power is placed on-board the system to allow for tether less missions involving distant travel. The system is responsible for high-level decision-making, motion control, autonomous path planning, and execution. The cost of the STAR is dependent on the sensor package attached. The STAR is equipped with a differential GPS system for autonomous operation and it can accommodate the Micro-power Impulse Radar (MIR) for landmine detection technology developed by LLNL. A disadvantage of STAR is the high friction between the screw wheels and the ground, which keeps the machine to a one-and-a-half-mileper-hour speed limit while moving forward or backward. STAR has been studied in specific mine projects. The robot is not suitable for environments that are full of rocks. 
Experiments have shown the ability of STAR to negotiate successfully, hard and soft soils, sand, pavement, mud, and water. No demining testing and evaluation were reported.

\subsubsection{COMET I, II and III: Six legged Robot (Chiba University in Japan)}

COMET I and II have six legs and is equipped with several sensors for mine detection (Nonami, 1998). COMET III has 2 crawler and 6 legs walking/running robot with two arms in the front. It is driven by hydraulic power. The robot weight $990 \mathrm{~kg}$, its length $4 \mathrm{~m}$, width $2.5 \mathrm{~m}$, and height $0.8 \mathrm{~m}$. The COMET is made of composite material for legs and manipulators like CFRP to reduce the total weight. Currently, COMET-I can walk slowly at speed $20 \mathrm{~m}$ per hour with precise detection mode using six metal detectors. On the other hand, COMET-II can walk at speed $300 \mathrm{~m}$ per hour with precise detection mode using the mixed sensor with metal detector and GPR at the tip of the right manipulator. COMET robots are equipped with CCD camera, IR camera and laser sensor. Different experiments haven been conducted to detect artificially located mines based on the use of infrared sensors that can deal with different terrain (Nonami et al., 2000).

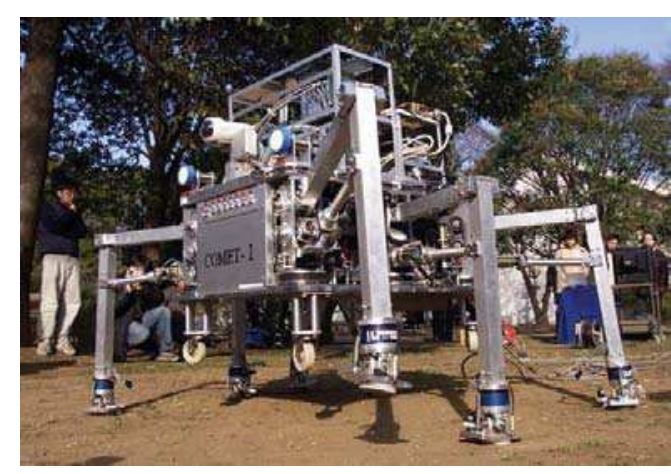

COMET I

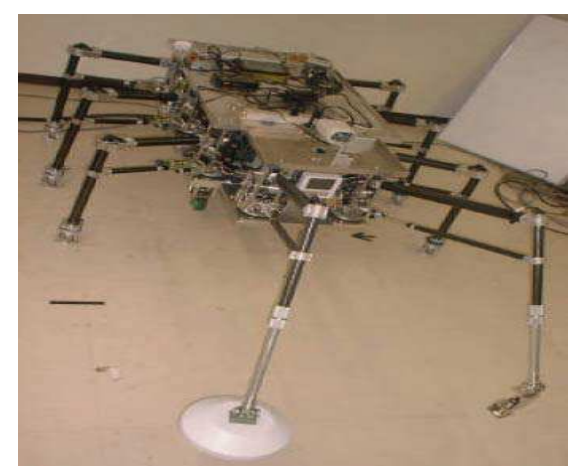

COMET II

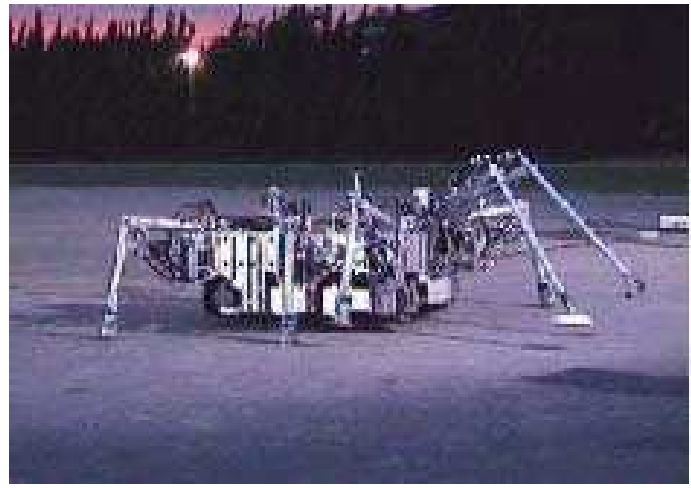

COMET III

Fig. 14. Different versions of the six legged mobile robot COMET. 


\section{Conclusions}

The major technical challenge facing the detection of individual mine, is having the ability to discriminate landmines from metal debris, natural clutters and other objects without the need for vegetation cutting. Future efforts to improve detection should focus on providing a discrimination capability that includes the fusion of information coming from multi heterogeneous and homogenous sensors and the incorporation of advanced signal processing techniques to support real-time processing and decision making. For the purpose of mine clearance, there is an urgent need to have cost-effective and efficient clearance techniques to clear landmines in all types of terrains. This should be associated with neutralization, in which there is a need to develop safe, reliable, and effective methods to eliminate the threat of individual mines without moving them.

Working in a minefield is not an easy task for a robot. Hostile environmental conditions and strict requirements dictated by demining procedures make the development of demining robots a challenge. Demining robots offer a challenging opportunity for applying original concepts of robotic design and control schemes, and in parallel to this there is urgent need to develop new mine detection techniques and approaches for sensor integration, data fusion, and information processing.

Difficulties can be recognized in achieving a robot with specifications that can fulfil the stated requirements for humanitarian demining. A lot of demining tasks cannot yet be carried out by the available robots because of their poor locomotive mechanism and mobility in different type of terrains. This is because there is still lack of well-adopted locomotion concepts for both outdoor and off-road locomotion. Hence, there is a need to develop modular, light-weight, and low-cost mobile platforms that can deal with different terrain. Modularized robotic solutions properly sized and adaptable to local minefield conditions is the best way to enable reconfiguration that suite the local needs, greatly improve safety of personnel as well as improving efficiency. In order to be able to design and build successful robot, it is necessary to carefully study conditions and constraints of the demining operations. The technologies to be developed should take into account the facts that many of the demining operators will have had minimal formal education and that the countries where the equipment are to be used will have poor technological infrastructure for servicing and maintenance, spare parts storage, operation and deployment/logistics.

Research into individual, mine-seeking robots is still in the early stages. In their current status, they are not an appropriate solution for mine clearance. Due to the gap between scientists developing the robots and the deminers in the field, and because none of the developed robots (specifically these presented in section 10.3) yet entered a minefield for real and continuous mine detection and removal. Several large research efforts have failed so far, to develop an effective mine clearance alternative to the existing manual technique. Robots have been tried at great expense, but without success yet. There is still a large amount of skepticisms on the role and use of autonomous robots for demining purposes. Expert in robotics knows too little about the practical challenge of demining: hence the robot is designed like all other autonomous robots attempting to navigate an unknown environment. Although some aspects of navigation may be extended to demining robots, it will be more reliable if robots were designed specifically for the purpose of landmine detection than as an after thought. Understanding the current and previous failed research efforts may help to avoid 
similar mistakes. Detecting and removing AP mines seems to be a perfect challenge for robots. But, this requires to have a good understanding of the problem and a careful analysis must filter the goals in order to avoid deception and increase the possibility of achieving results.

The approach to solve the humanitarian demining problem and fulfill its needs requires a strategy for research and development with both short and long-term components. In the short and mid terms, robots can help to accelerate searching and marking mines. In addition, it can be helpful to be used for quality assurance stage for verification purposes. High cost and high tech features are additional constraints in using robots for demining. Any single breakthrough in technology should be viewed as yet another tool available for use in the demining process, and it may not be appropriate under all conditions. Furthermore, careful study of the limitations of any tool with regard to the location and environment is critical; not all high-tech solutions may be workable at all places. The knowledge required to operate a machine may not match the skill level of the deminers, many of whom are drawn from the local public. In addition, cost of maintenance, spare parts and its availability are critical parameters too. While current technology may be slightly effective, it is far too limited to fully address the huge mine problem facing the world.

\section{References}

Blagden, P. M. (1993). Summary of UN Demining. Proceedings of the International Symposium on Anti-Personnel Mines, Montreux, April 1993, CICR/ICRC, pp 117-123.

Bruschini, C.; Bruyn, K. De; Sahli, H. \& Cornelis, J. (1999). EUDEM: The EU in Humanitarian DEMining. EU report, Brussels, 1999.

Burke, S. (2003). The U.S. Department of Defense Humanitarian Demining Research and Development Program. Journal of Mine Action, Vol. 7, No. 1, April 2003.

Cain, B. \& Meidinger, T. (1996). The Improved Landmine Detection System. EUREL, 1996, pp. 188-192.

Danielson, G. \& P. Blachford, P. (2003). DIANA 44T Test and Evaluation - August 2003. Ref.: 13 345:60629, Swedish Armed Forces, Swedish EOD and Demining Centre, 2003.

Danielsson, G. \& G. Coley, G. (2004). Minecat 140 Test and Evaluation - Sept. 2003. Ref.: 13 345:60099, Swedish Armed Forces, Swedish EOD and Demining Centre, 2004.

Dawson-Howe, K. M. \& Williams, T. G. (1997). Automating the probing process. Proceedings of the International Workshop on Sustainable Humanitarian Demining (SusDem'97), Zagreb, Croatia, Oct.1997, pp. 4.24-4.29.

Department of Defense, Humanitarian Demining Research and Development (R\&D) Program (2002). Other Completed Mine/Vegetation Clearance Equipment. Development Technologies Catalog 2001-2002.

Eisenhauer, D. J., Norman, C. O., Kochanski, F. K., and Foley, J. W. (1999). Enhanced Teleoperated Ordnance Disposal System (ETODS) for Humanitarian Demining. Proceedings of the 8th International Meeting of the American Nuclear Society (ANS), Pittsburgh, PA, April 1999.

E. S. Inc. MR-2 Demining and Hazardous Materials Handling Robot. Available online at (2005-03-23): http://www.esit.com/mobile-robots/mr2.html.

Espirit HPCN, (1997). Industrial R\&D Requirements for Humanitarian Demining. (Available through <http://www.cordis.lu/espirit/src/report43.html/). 
Estier, T.; Piguet, R.; Eichhorn, R. \& Siegwart, R. (2000a). Shrimp, a Rover Architecture for Long Range Martian Mission. Proceedings of the Sixth ESA Workshop on Advanced Space Technologies for Robotics and Automation (ASTRA'2000), Netherlands, Dec. 5-7.

Estier, T.; Crausaz, Y.; Merminod, B.; Lauria, M.; Piguet, R. \& Siegwart, R. (2000b). An Innovative Space Rover with Extended Climbing Abilities. Proceedings of Space and Robotics 2000, Albuquerque, USA, February 27-March 2, 2000, pp. 333-339.

Fyfe, K. R. (1996). A Mechanical Means of Land Mine Detection. University of Alberta, Department of Mechanical Engineering, 1996, Canada. http://www.mece.ualberta.ca/ staff/fyfe/landmine.html

Gage, D. W. (1995). Many-robot MCM Search Systems. Proceedings of the Autonomous Vehicles in Mine Countermeasures Symposium, Monterey, CA, April 1995, pp.9.56-9.64.

Geneva Centre for Humanitarian Demining, (2006). Mechanical Demining Equipment Catalogue. Geneva Centre for Humanitarian Demining, Geneva, Switzerland.

Goose, S. (2004). Overview of Antipersonnel Mine Stockpile Destruction. ICBL Treaty Working Group, June 2004.

Guccione, S. \& Muscato, G. (2003). Control Strategies Computing Architectures and Experimental Results of the Hybrid Robot Wheeleg. IEEE Robotics and Automation Magazine, (IEEE Piscataway, U.S.A.), Vol.10, N.4, December 2003, pp. 33-43.

Habib, M. K. (1998). Multi Robotics System for Land Mine Clearance. Proceedings of the International Conference on Robotics and Computer Vision (ICRACV'98), Singapore, Dec. 1998.

Habib, M K. (2001a). Mine Detection and Sensing Technologies: New Development Potentials in the Context of Humanitarian Demining. Proceedings of the IEEE International Conference of Industrial Electronics, Control and Instrumentation (IECON'2001), USA, 2001, pp. 1612-1621.

Habib, M. K. (2001b). Machine Assisted Humanitarian Demining Mechanization and Robotization", Proceedings of the International Field and Service Robots'2001, Finland, pp. 153-160.

Habib, M. K. (2002a). Mechanical Mine Clearance Technologies and Humanitarian Demining: Applicability and Effectiveness. Proceedings of the $5^{\text {th }}$ International Symposium on Technology and Mine Problem, California, USA, April 2002.

Habib, M. K. (2002b). Mine Clearance Techniques and Technologies for Effective Humanitarian Demining. International Journal of Mine Action, Vol.6, No.1, 2002.

Healy, A. \& W., Webber, W. (1993). Sensors for the Detection of Land-based Munitions. Naval Postgraduate School, Monterey, California, N PS-M E-95-003, September 1993.

Hewish, M. \& Ness, L. (1995). Mine-detection Technologies. International Defense Review, October 1995, pp. 40-46.

Humanitarian Mine Action Equipment Catalogue (1999), German Federal Foreign Office.

Institute for Defense Analyses (2005). Proof of Performance Test Report on Mine Clearing/Survivable Vehicle. Alexandria-USA, March 2005.

International Committee of Red Cross (1996a). Antipersonnel Mines: An Overview. Geneva, September 1996. (See also: http://www.icrc.org/).

International Committee of Red Cross (1996b). Antipersonnel Mines- Friends or Foe? ICRC Publication, Ref. 0654, Geneva, 1996.

International Committee of Red Cross (1998). The Silence Menace: Landmines in Bosnia and Herzegovina. ICRC Publication, Ref. 2160, Geneva, 1998. 
International Test and Evaluation Program for Humanitarian Demining (ITEP), (2006). ITEP Work Plan 2000-2005. Portfolio of the ITEP Participant's finalized test and evaluation activities, March 2006.

Kentree Ltd, Kilbrittain, Co Cork, Ireland

King, C. (1997). Mine Clearance in the Real World. Proceedings of the International Workshop on Sustainable Humanitarian Demining, Zagreb (SusDem'97), pp. S2.1-8.

Leach, C. (2004). Bozena 4 Mini Mine Clearance System Assessment Phase 1: QinetiQ/FST/LDS/CR044502/1.0. Farnborough, 2004.

Leach, C.; Blatchford, P.; Coley, G. \&, J. Mah, J. (2005). TEMPEST V system with Ground Engaging Flail Cambodia Trials Report. Farnborough: NETIQ/FST/LDS/TRD052379, 2005. p. 3

McFee, J. E. (1996). Multisensor Mine Detector for Peacekeeping: Improved Landmine Detector Concept. SPIE Technical Conference 2765, March 1996.

Muscato, G. \& Nunnari, G. (1999). Leg or Wheels? WHEELEG a Hybrid Solution. Proceedings of the International conference on climbing and Walking Robots (CLAWAR'99), Portsmouth, U.K., 14-15 September 1999.

Nicoud, J.-D. \& Habib, M. K. (1995). PEmex-B Autonomous Demining Robots: Perception and Navigation Strategies. Proceedings of the IEEE/RSJ International Conference on Intelligent Robots and Systems (IROS'95), Pittsburgh, August 1995, pp. 419-424.

Nicoud, J.-D. (1996). A Demining Technology Project. Proceedings of the International Conference on Detection of Abandoned Land Mines (MD'96), Edinburgh UK, October, 1996, pp.37-41.

Nicoud, J-D. \&. Machler, Ph. (1996). Robots for Anti-Personnel Mine Search. Control Engineering Practice, Vol. 4, No. 4, pp. 493-498.

Nicoud, J.-D.; Guerne, F. \& Brooks, J. (1998). Report on the DeTec-2 Testing in Cambodia Nov. 18-21, 1997. The Journal of Humanitarian demining, Vol.2, No.2, 1998.

Nonami, K. (1998). Robotics for Humanitarian Demining. Proceedings of the $9^{\text {th }}$ International Conference on Advanced Robotics (ICAR'98), Tokyo, 1998, pp. 591-594.

Nonami, K.; Huang, Q.J.; Komizo, D.; Shimoi, N. \& Uchida, H. (2000). Humanitarian Mine Detection Six-Legged Walking Robot. Proceedings of the 3rd International Conference on Climbing and Walking Robots, Madrid, Spain, 2000, pp. 861-868.

OAO-Robotics, OAO Robotics. Remote Operated Mine Detector website http://www.manitgroup.com/oao.htm

O'Malley, T. J. (1993). Seek and Destroy - Clearing Mined Land. Armada International, Vol. 17, No. 1, February-March 1993, pp 6-15.

Perez, M. L. (1996). A Low-Cost Multi-Terrain Autonomous Vehicle for Hostile Environments. UCRLFJC-124S0, Technical Information Department, Lawrence Livermore National Laboratory, University of California, Livermore, California 94551, December 1996.

Physicians for Human Rights (1993). Landmines, A Deadly Legacy. Human Rights Watch, New-York, 510p, ISBN 1-56432-1 134

Republic of Croatia, Croatian Mine Action Centre (CROMAC) (2202). Testing of MV-4 Mine Clearing Machine, Sisak, May 2002.

Salter, S. H. \& Gibson, CNG. (1999). Map-Driven Platforms for Moving Sensors in Mine Fields. Mine Action Information centre Journal, Vol.3, No.2, Summar 1999.

Sieber, A. (1995). Localisation and Identification of Anti-personnel Mines. Joint Research Centre, European Commission, EUR 16329N, 1995. 
Treveylan, J. (1997). Robots and Landmines. Industrial Robots, Vol. 24, No. 2, pp. 114-125.

US Department of Defense, (1999). Humanitarian Demining Development Technologies. Catelogue, USA, 1998.

US Department of State (1994). Hidden Killers: The Global Landmine Crisis. Report to Congress, Washington D. C., Publication 10225, December 1994 (See also: http:/ / www.state.gov/

Van Westen, C. J. (1993). Remote Sensing and Geographic Information Systems for Geological Hazard Mitigation. ITC-Journal, No. 4, 1993, pp. 393-399. 


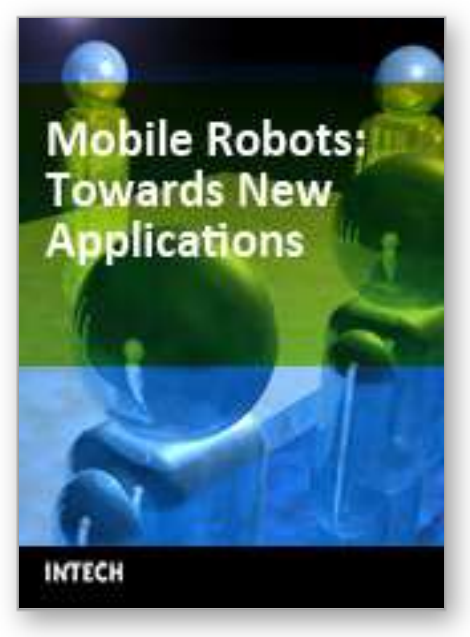

\author{
Mobile Robots: towards New Applications \\ Edited by Aleksandar Lazinica
}

ISBN 978-3-86611-314-5

Hard cover, 600 pages

Publisher I-Tech Education and Publishing

Published online 01, December, 2006

Published in print edition December, 2006

The range of potential applications for mobile robots is enormous. It includes agricultural robotics applications, routine material transport in factories, warehouses, office buildings and hospitals, indoor and outdoor security patrols, inventory verification, hazardous material handling, hazardous site cleanup, underwater applications, and numerous military applications. This book is the result of inspirations and contributions from many researchers worldwide. It presents a collection of wide range research results of robotics scientific community. Various aspects of current research in new robotics research areas and disciplines are explored and discussed. It is divided in three main parts covering different research areas: Humanoid Robots, Human-Robot Interaction, and Special Applications. We hope that you will find a lot of useful information in this book, which will help you in performing your research or fire your interests to start performing research in some of the cutting edge research fields mentioned in the book.

\title{
How to reference
}

In order to correctly reference this scholarly work, feel free to copy and paste the following:

Maki K. Habib (2006). Service Robots and Humanitarian Demining, Mobile Robots: towards New Applications, Aleksandar Lazinica (Ed.), ISBN: 978-3-86611-314-5, InTech, Available from:

http://www.intechopen.com/books/mobile_robots_towards_new_applications/service_robots_and_humanitaria n_demining

\section{INTECH}

open science | open minds

\author{
InTech Europe \\ University Campus STeP Ri \\ Slavka Krautzeka 83/A \\ 51000 Rijeka, Croatia \\ Phone: +385 (51) 770447 \\ Fax: +385 (51) 686166 \\ www.intechopen.com
}

\author{
InTech China \\ Unit 405, Office Block, Hotel Equatorial Shanghai \\ No.65, Yan An Road (West), Shanghai, 200040, China \\ 中国上海市延安西路65号上海国际贵都大饭店办公楼 405 单元 \\ Phone: +86-21-62489820 \\ Fax: +86-21-62489821
}


(C) 2006 The Author(s). Licensee IntechOpen. This chapter is distributed under the terms of the Creative Commons Attribution-NonCommercial-ShareAlike-3.0 License, which permits use, distribution and reproduction for non-commercial purposes, provided the original is properly cited and derivative works building on this content are distributed under the same license. 